\title{
Monitoring - the good, the bad and the ugly
}

\author{
PJN Pells Pells Consulting, Australia
}

\begin{abstract}
This paper was prepared for the opening address at the symposium and is intended to provide material for contemplation whilst considering the latest in monitoring and communications. By examining case studies ranging from the successful to the disastrous, and by considering modern understanding as to how we humans think, it is hoped that the issues raised will provide an appropriate framework for the symposium.
\end{abstract}

\section{Introduction}

In our day and age, as will be demonstrated by numerous papers at this symposium, we have remarkable ability to monitor geotechnical and groundwater works. We can monitor pore pressures, strains, displacements, temperature, chemical signals, air quality, vibrations, and so on, at remote sites and deep in the earth, and we can stream the data to our offices, homes and smart phones in real time. We can fly drones to give us aerial scans from any angle, and we can wave LiDAR scanners by hand in underground openings to give us 3D images.

If I had tried to summarise the state of the art for this presentation I would have been out of date before the symposium started. So that is not my purpose; my purpose is to make us ask three questions:

1. Why are we monitoring whatever we are monitoring?

2. Against what expectations and criteria are we going to interpret the results?

3. What unconscious bias do we carry in respect of interpreting the results?

As a matter of principle, I do not accept the answers to be encapsulated in:

"I will monitor everything I can think of and hope that the data will show me something."

Such an answer may be acceptable for academic studies, and may help forensic experts when working out why your project went wrong. Designers and contractors need to take a different view, as I will summarise after presenting some case studies of the good, the bad and the ugly.

\section{The good}

\subsection{Leonardo da Vinci}

Somewhere between 1478 and 1518, Leonardo da Vinci ventured briefly into the engineering geology of landslides, and recommended what remains today fundamental to monitoring thereof.

His sketch of a natural landslide (Codex Arundel IV) showing shearing along inclined bedding, is given in Figure 1. His advice is as follows:

"In order to find the solid part of these strata, it is necessary to make a shaft at the foot of the wall of great depth through the strata; and in this shaft, on the side from which the hill slopes, smooth and flatten a space one palm wide from the top to the bottom; and after some time this smooth portion made on the side of the shaft, will show plainly which part of the hill is moving." 


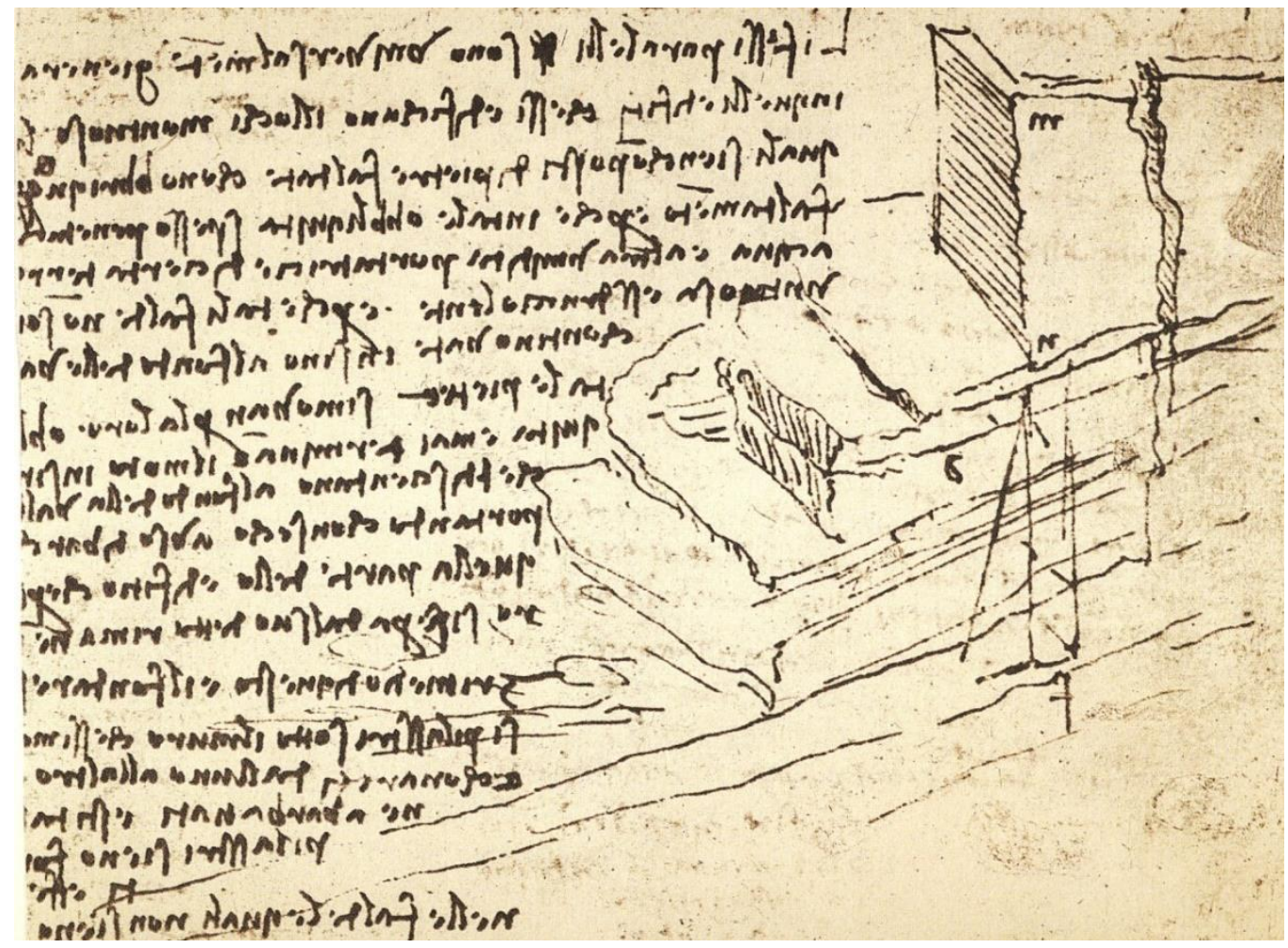

\section{Figure 1 Leonardo's investigation of a shear plane in a natural landslide}

We may nowadays choose to use inclinometers rather than hand dug shafts, but the principle remains the same. Understand the geology monitor appropriately, and you will probably understand a landslide.

\subsection{The Opera House carpark, Sydney}

Two hundred and seventeen years ago when the first Europeans viewed Sydney Cove, they could see on the eastern side of the bay, a long spit of land which was almost entirely composed of a $10 \mathrm{~m}$ depth of bleached shell left behind after thousands of years of Aboriginal meals. For fifty years, it provided the new settlement with the raw material for lime manufacture. Later Fort Macquarie was built on this point (Figure 2). In 1902, the fort was demolished, fill was placed and a large tram terminus building was constructed (Figure 3). This was demolished in the 1960s for construction of the Opera House.

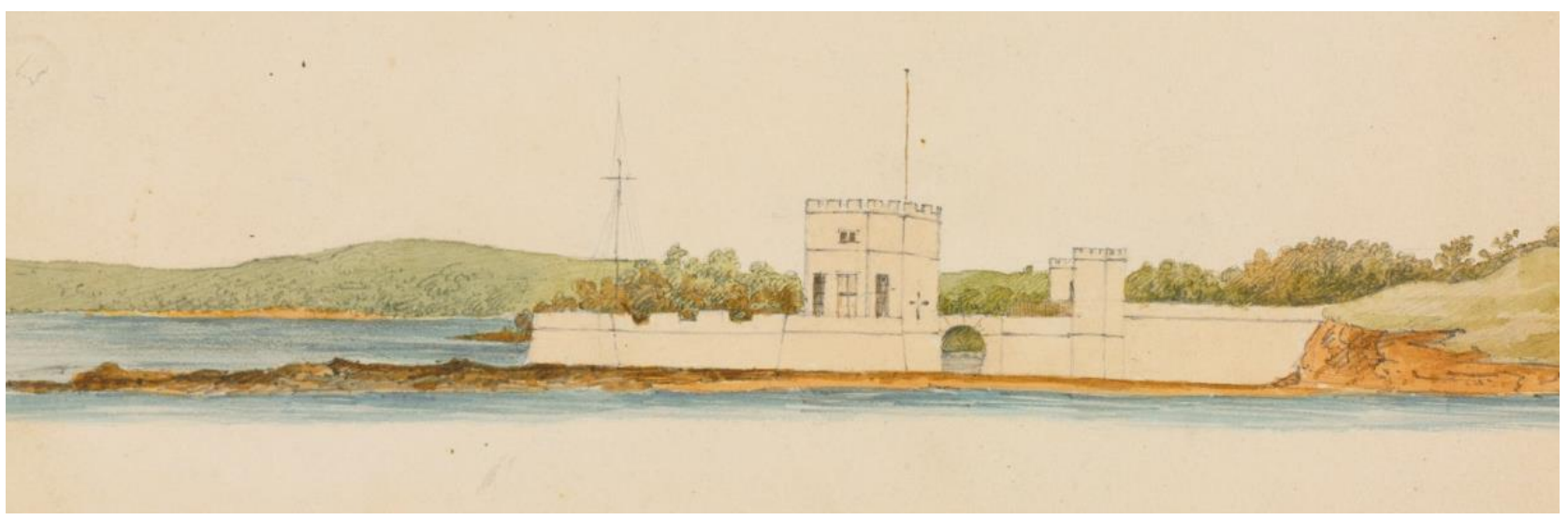

Figure 2 Bennelong Point with Fort Macquarie (Pells 2011) 


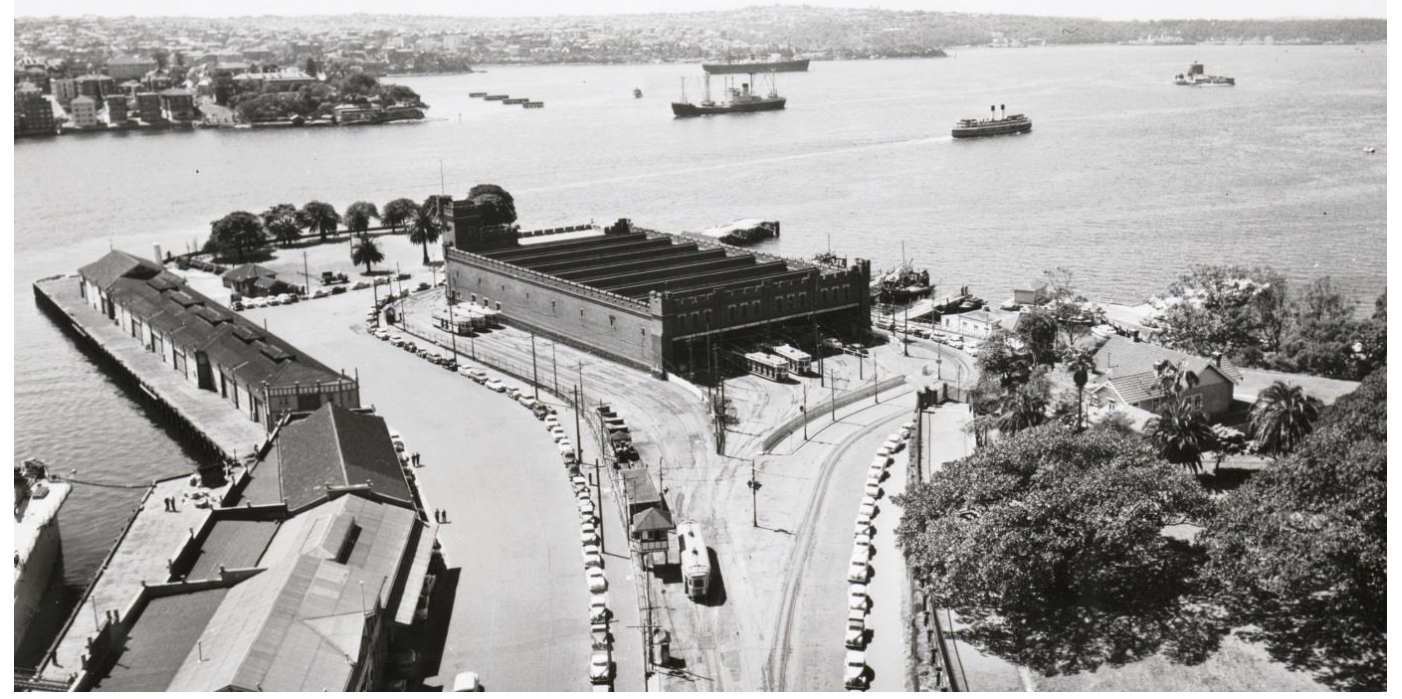

\section{Figure 3 The beautiful tram shed on Bennelong Point}

The Tarpeian Way, which runs just inside the railing of the Botanic Gardens, was so named because of a very large sandstone outcrop on Bennelong Point. Governor Phillip's officers called it the Tarpeian Rock after that rock in Ancient Rome from which traitors were tossed. It was quarried in about 1817 to form the clean cut face that we now see (Figure 4). It is this sandstone unit which forms the roof of the Sydney Opera House underground parking station.

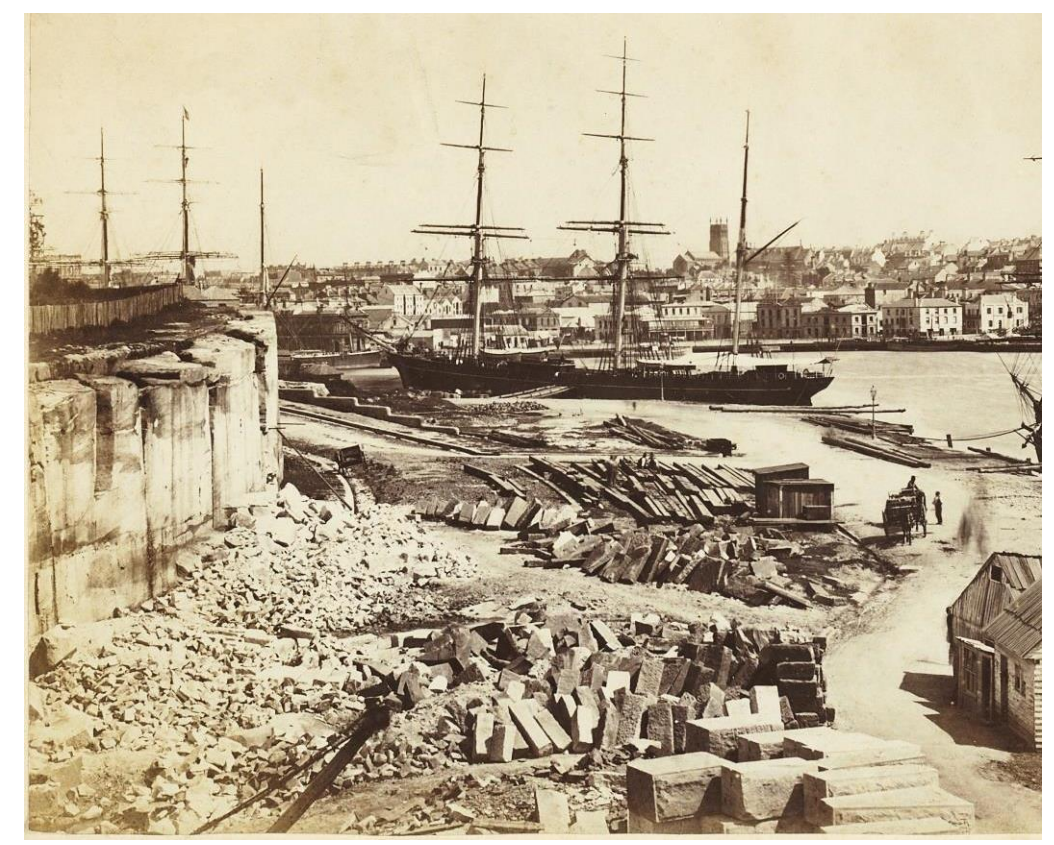

\section{Figure 4 Face of quarry exposing the sandstone that is the roof of the Opera House Carpark}

The parking station is a free standing double helix concrete structure in a donut shaped cavern. The helical concrete structure does not touch, or support, the cavern roof or sidewalls.

The cavern has an outer diameter of $71.5 \mathrm{~m}$, with a central rock column $36.4 \mathrm{~m}$ in diameter (Figure 5). Parking space requirements dictated a free span of $17.5 \mathrm{~m}$.

The vehicle access tunnels pass over the top of the Sydney Harbour Tunnel. This made it necessary to design the cavern crown as close as possible to the ground surface, resulting in overburden cover of about $6 \mathrm{~m}$ of sandstone. 


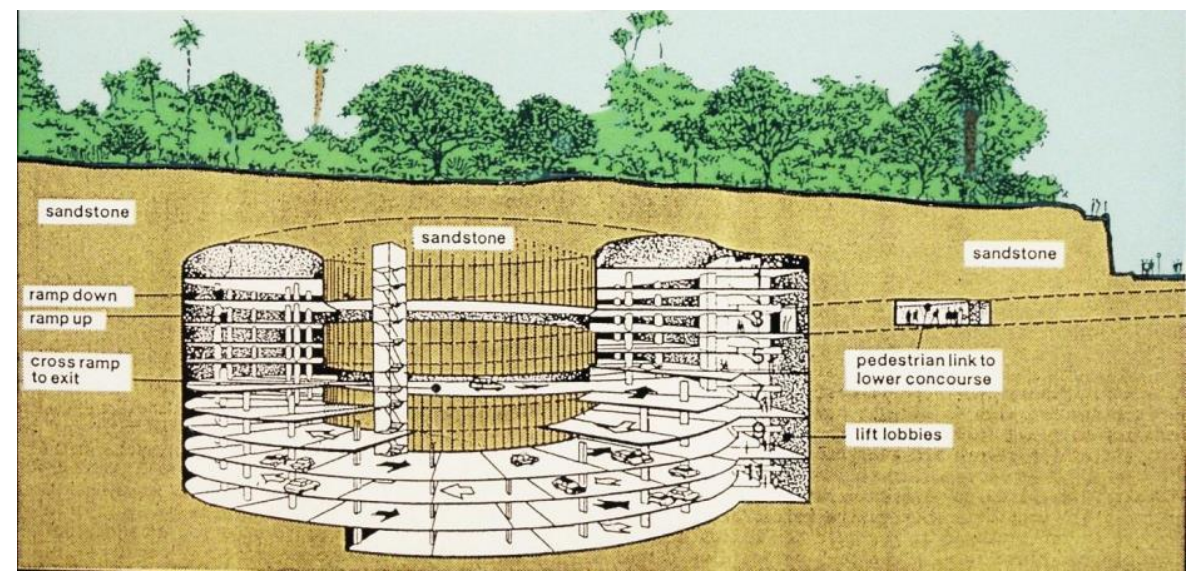

\section{Figure 5 3D sketch of the double helix in its cavern}

The design of the cavern roof represented the fortunate convergence of ideas. For years we had been developing the idea proposed by Evans (1941) that a thick beam of rock can span very substantial distances, provided its integrity can be maintained. The design and construction in 1988/89 of the flat roof of the $13.5 \mathrm{~m}$ wide Bondi pumping station gave further confidence (Pells \& Best 1991). The evidence suggested we could create the $17.5 \mathrm{~m}$ span at Bennelong with only $6 \mathrm{~m}$ of rock cover. However, there was no coherent analytical design method.

The late Dr Booker reworked Evans' linear arch theory so that the line of thrust did not have to be guessed but was calculated using one-dimensional finite element theory. This allowed studies to be made of both deformation and the stability of a roof beam by varying mass modulus, beam fixity, stress field and loading.

The analyses showed that $6 \mathrm{~m}$ of massive sandstone could span $17.5 \mathrm{~m}$ with a predicted deflection of about $10 \mathrm{~mm}$ and a safety factor of greater than 10 against compressional failure at the haunches. The problem was that the real 6 to $7 \mathrm{~m}$ of sandstone comprised beds 1 to $2 \mathrm{~m}$ thick, so it was necessary to design a reinforcing system which would make this laminated system act as a single $6 \mathrm{~m}$ thick, no tension, pseudo-elastic medium. There were many parameters that had to be estimated for this design and we were acutely aware of the consequences if we were wrong.

Calculations were made as to how crown sag would increase with sequentially increased span, as the key design idea was to use monitoring of crown sag as the span was progressively increased, to prove, or disprove, the design assumptions. The original diagram showing calculated crown deflection as a function of increasing span is given in Figure 6.

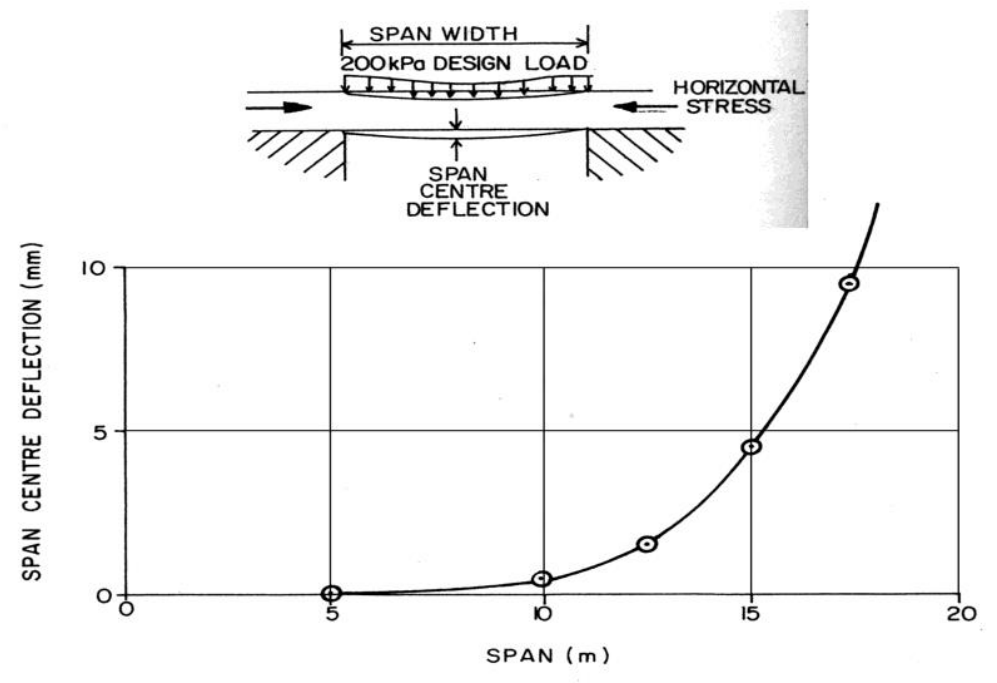

Figure 6 Design predictions of crown deflection versus increasing span (1990) 
Construction was programmed so as to increase the crown span in steps (Figure 7), with monitoring of crown sag, surface settlement and rock mass dilation, specifically established to allow comparison of field reality with design modelling. This monitoring was explicitly set up to allow verification, or otherwise, of the design expectations and to ensure that unexpected and unacceptable performance was determined before a disastrous situation could develop.

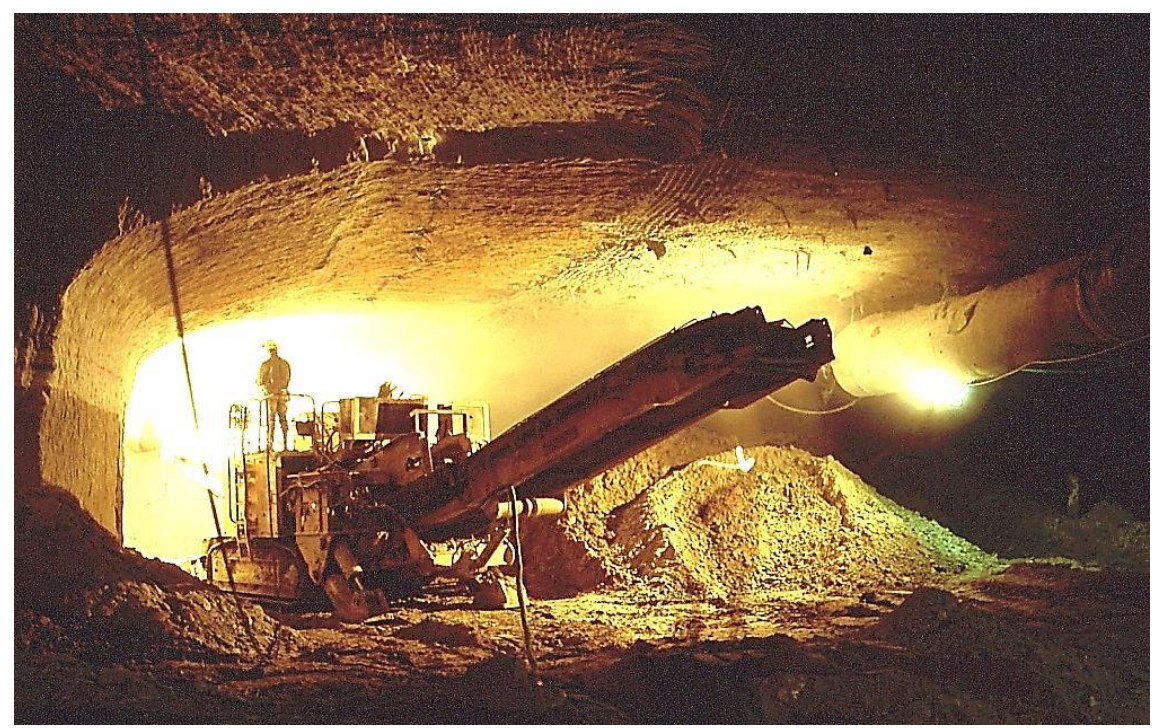

Figure 7 Incremental widening of the crown of the carpark donut-cavern

Figure 8 shows the comparison between measured crown sag, as the span increased, with the design stage predictions. Comparison of surface subsidence with internal sag measurements showed that the sag over centre span was directly transferred to the surface. This agreed with extensometer measurements which showed typical bed separation of about $1 \mathrm{~mm}$.

These data gave us confidence that the actual rock mass behaviour was consistent with our models, and that the design was appropriate.

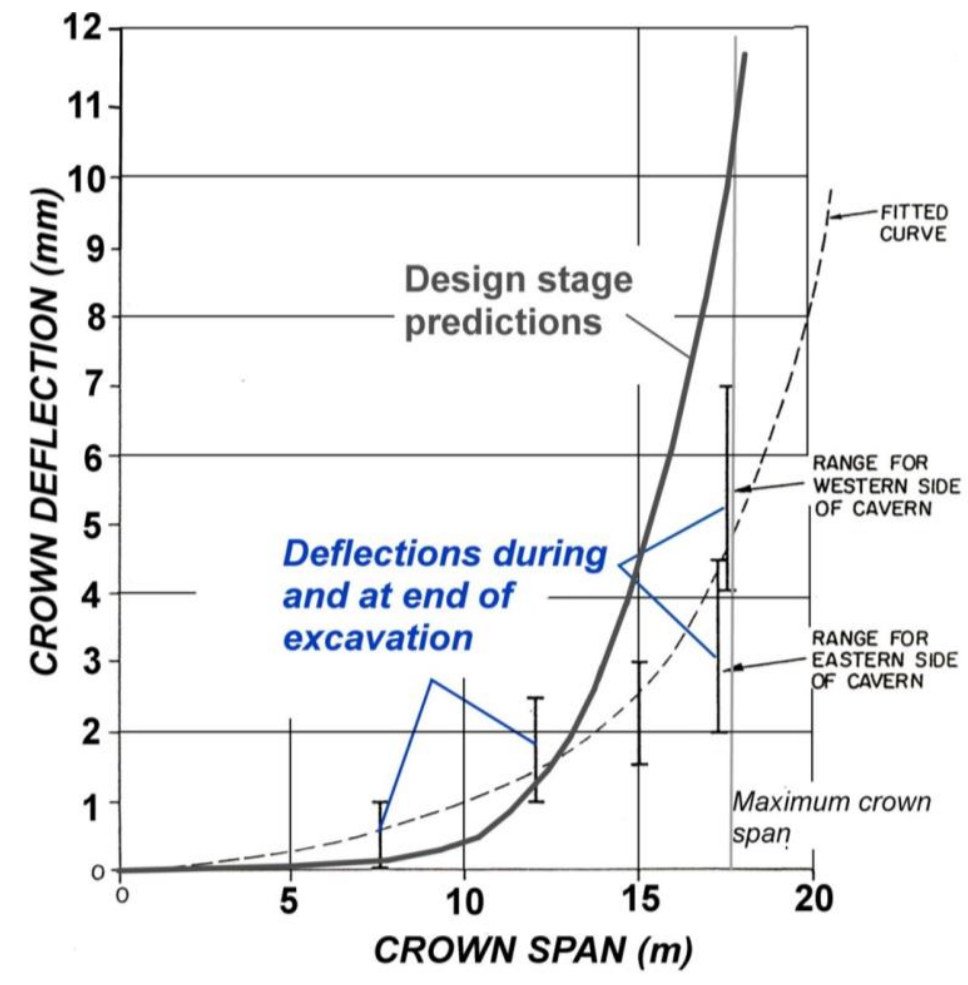

Figure 8 Comparison between design calculations and construction monitoring 
There was more to the monitoring instrumentation than summarised above, but for the purpose of this paper, the material presented is sufficient to show key thought processes relevant to the monitoring.

As an aside, it is now 20 years since completion of the carpark. Ongoing monitoring has revealed some behaviour different to that expected at design stage.

The first is that the massive, circular sandstone pillar, $36.5 \mathrm{~m}$ diameter and $37 \mathrm{~m}$ high has compressed about $15 \mathrm{~mm}$; mostly, we think, by shrinkage associated with being completely dried.

The second is that creep movements of the crown have been greater than expected, amounting to an additional maximum crown sag, and surface settlement, of about $5 \mathrm{~mm}$.

\section{A bad outcome but good input - Golden Cross}

\subsection{Location: Golden Cross mine, New Zealand}

In the early 1990s, Coeur d'Alene Mines bought the Golden Cross gold mine in the Coromandel Peninsula of New Zealand. This was an old underground mining area, and was opened up with a new open pit, processing plant and tailings dam. The area is beautiful and environmentally sensitive, and the mine infrastructure was developed with great care. Trout could be caught just downstream of the ore processing plant. As shown in Figures 9, 10 and 11, the tailings dam was on a hillside about $1 \mathrm{~km}$ upslope of the access road.

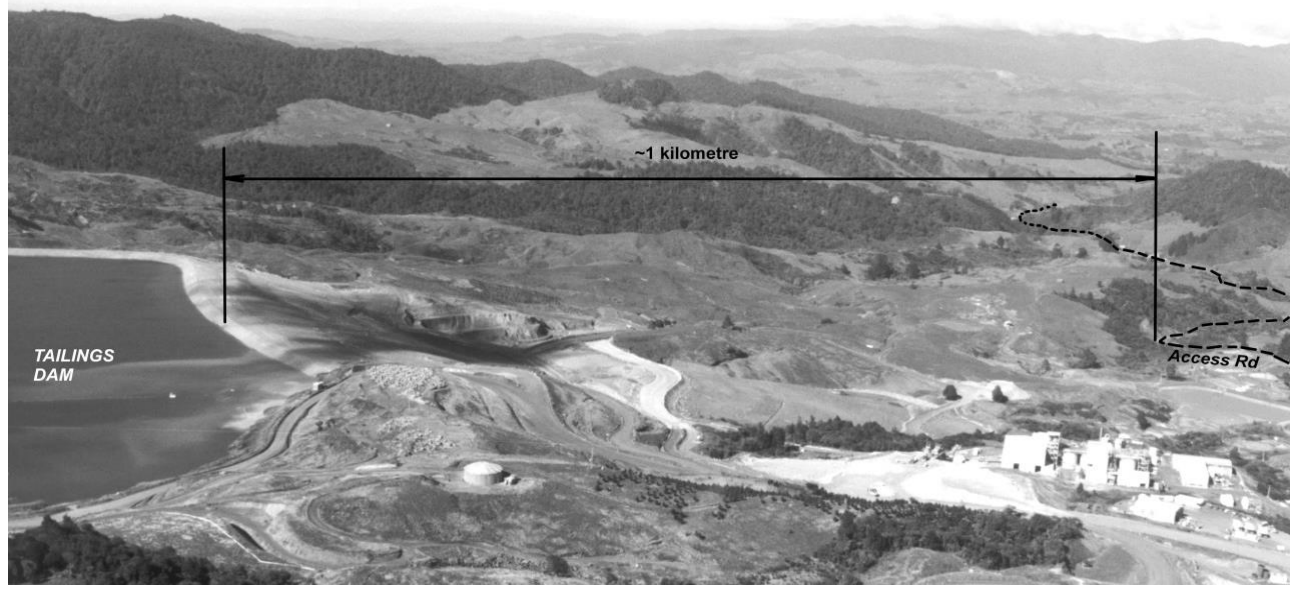

Figure 9 Golden Cross mine site - view to south

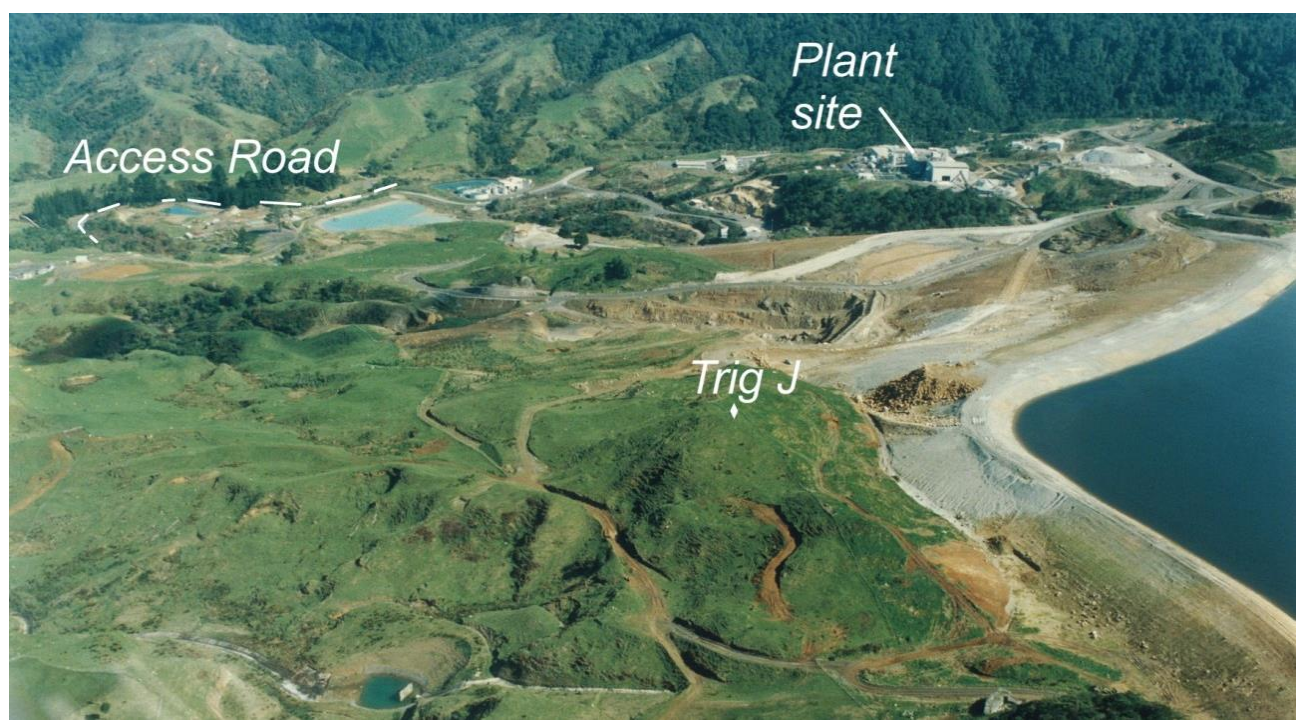

Figure 10 View to north-west 


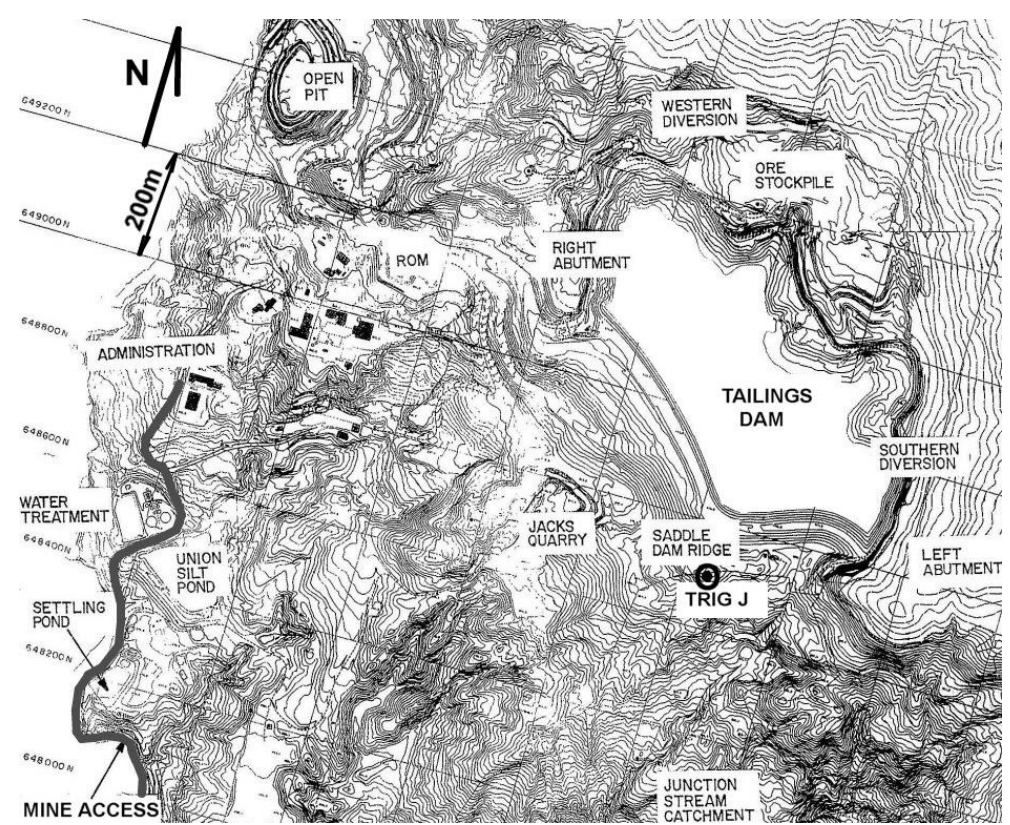

\section{Figure 11 Plan of Golden Cross mine site}

\subsection{The initial story}

Arriving at night on a site visit in April 1995, Tim Sullivan, consulting engineering geologist, recorded somewhere in his subconscious, certain bumps ('two steps' in his words) in the access road, south west and about $1 \mathrm{~km}$ downhill from the dam. He had been retained to give advice on the open pit, so thought no more about these bumps. Some months later (August) he drove the same road, again noted mentally that the bumps were different ('five steps'). The information was parked somewhere in his mind.

Meanwhile consultants were involved in design and monitoring of the tailings dam. Concerns had arisen regarding cracking in the left abutment area. Investigations had been undertaken. What were considered to be appropriate and comprehensive monitoring measures were established. However, all focus was on the area within about $200 \mathrm{~m}$ of the wall. The designers were confident that the issue had to be localised. Further fill was placed against the, already gentle, downstream face of the dam (Figure 12). However, as Nobel Laureate Kahneman (2011) says:

"Subjective confidence in a judgement is not a reasoned evaluation of the probability that this judgement is correct. Confidence is a feeling, which reflects the coherence of the information and the cognitive ease of processing it. It is wise to take admissions of uncertainty seriously, but declarations of high confidence mainly tell you that an individual has constructed a coherent story in his mind, not necessarily that the story is true." 


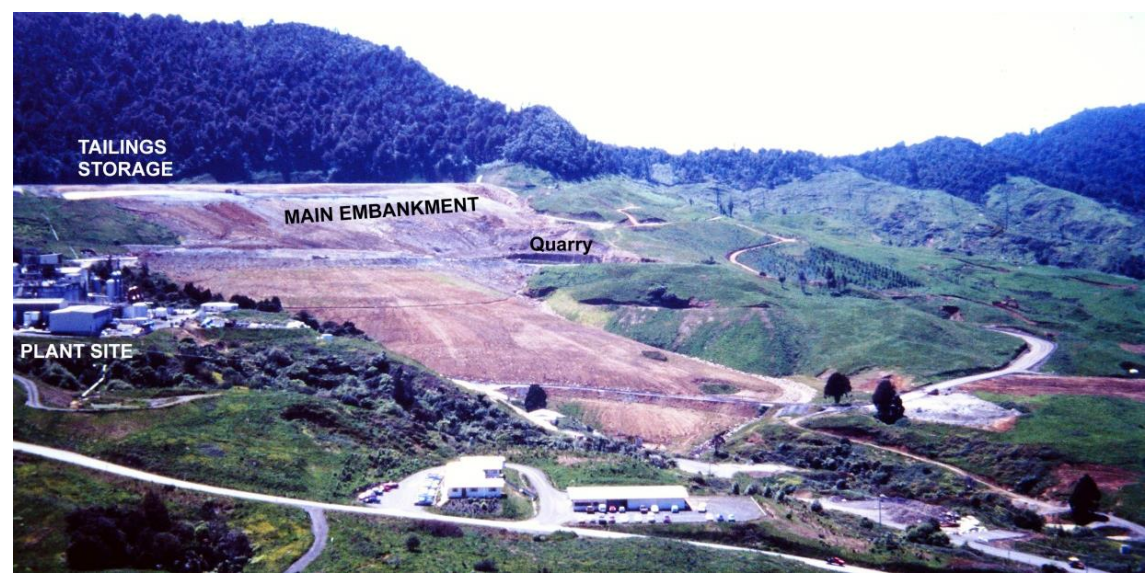

\section{Figure 12 Downstream face of the main embankment on hillside about $1 \mathrm{~km}$ above access road}

Movements continued, and the whole issue heated up when a crack, with associated shearing, opened about $100 \mathrm{~mm}$ at Trig J near the left abutment of the dam.

\subsection{A month later}

A month or so later, Tim Sullivan, Professor Robin Fell and I were retained to review the tailings dam issue. It did not take very long to put together the following additional facts and observations.

1. The geology beneath, and downhill of, the dam comprised:

- Ash, alluvial and colluvial deposits, overlying.

- Omahia Andesite, with an unconformable contact dipping $10^{\circ}$ west-south-west, overlying.

- Coromandel Volcanics (basement rock).

2. It had been known for decades that the contact between the Omahia Andesite and the smectite-rich, Coromandel Volcanics had played an important role in shaping the land. Four 'active faults' had been identified during investigations for the dam.

3. An area of tomos (Maori word for sinkhole) had been identified in the saddle embankment area during construction, and another within the reservoir area.

4. A potable water bore to the west of the tailings dam was blocked at a depth of $34 \mathrm{~m}$.

5. A monitoring bore, downhill of the saddle embankment ridge, was blocked at $25 \mathrm{~m}$.

6. A large slide had developed in the north wall of the open pit, controlled by sliding on the near horizontal Omahia-Coromandel contact.

On the basis of these observations, Sullivan postulated that Coeur d'Alene Mines could be dealing with a very large landslide (about $1.5 \mathrm{~km}$ downslope length, and $0.6 \mathrm{~km}$ width) of unknown depth, carrying the whole tailings dam along for the ride. It need hardly be said that this view did not go across very well. Strong views were expressed that the events and features listed above were unrelated, representing various localised near-surface instability features. Analyses of the localised monitoring system around the dam continued, and further localised remedial measures were undertaken.

Hoping to clinch the argument, an inclinometer was installed in a $100 \mathrm{~m}$ deep hole downslope of the dam. After a few weeks, there appeared the characteristic shear step, at a depth of $69 \mathrm{~m}$ (Figure 13). 


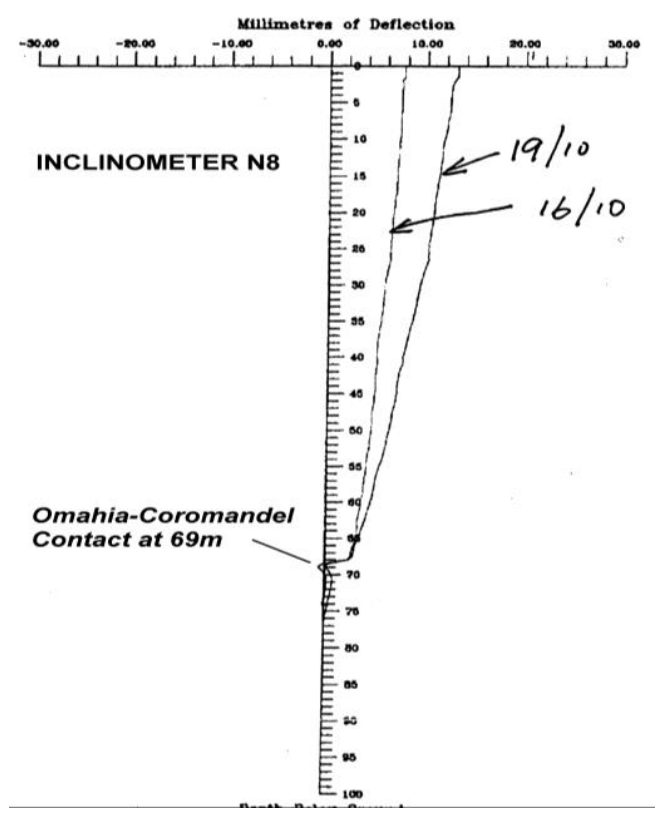

\section{Figure 13 Initial readings from Inclinometer N8}

Sullivan noted the 'noticeable deflection at the unconformity' in N8: but the designers of the dam, with all the emotional baggage that had to go with that position, recorded that "the plot of N8 at enlarged scale shows no significant movement has occurred at the kink and the apparent deformation is most likely settling-in."

Additional inclinometers replicated what by then very clear in N8 (Figure 14).

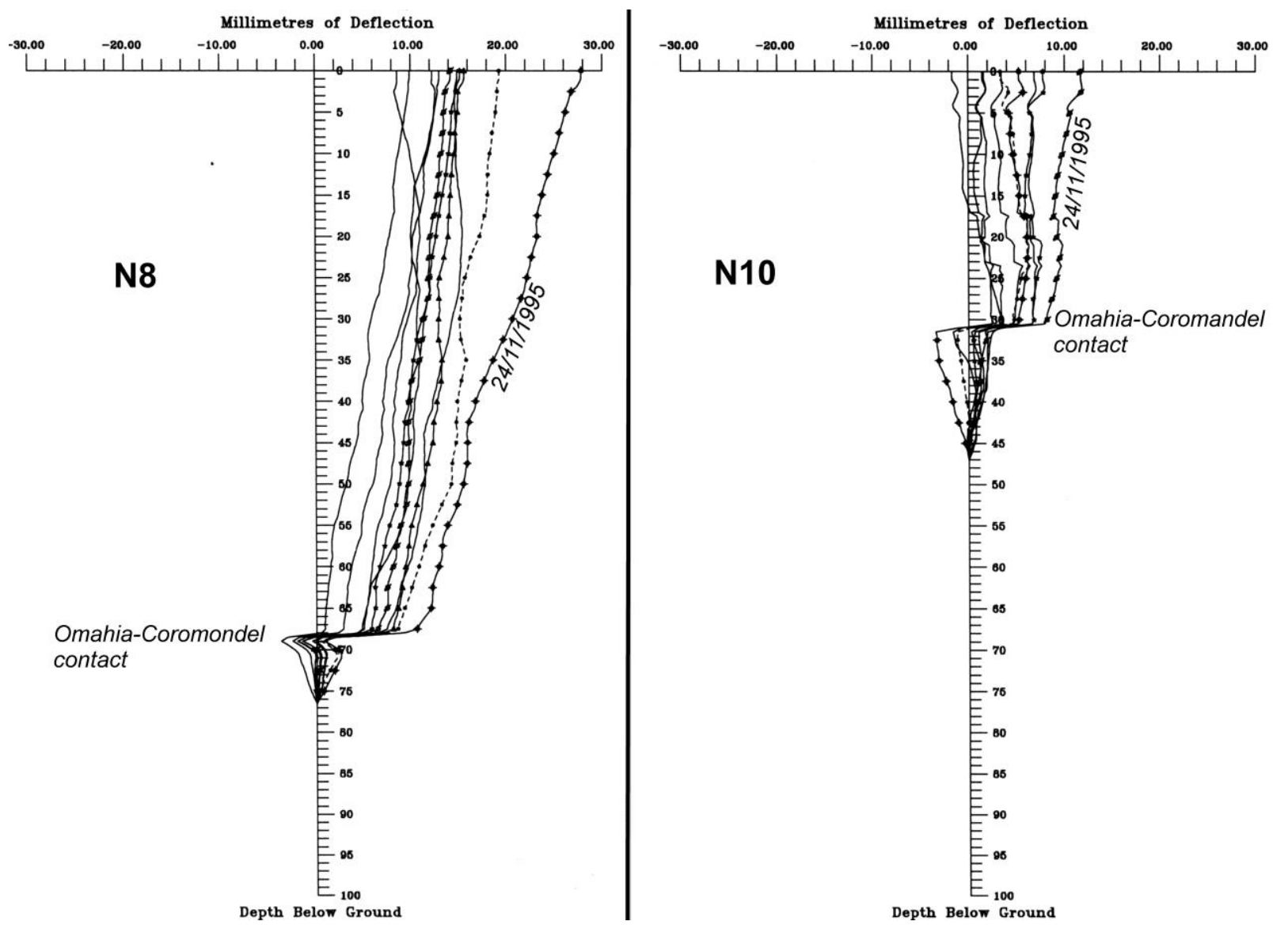

Figure 14 Inclinometers N8 and N10, 24 November 1995 
By early 1996, the following conclusions had been reached (Figures 15 and 16).

- The area containing, and to the south of the tailings embankment, was a large deep-seated translational landslide.

- The head of the slide was located upslope of the tailings embankment, and there was evidence to indicate a toe region west of the access road, a distance of over $1.5 \mathrm{~km}$.

- The basal shear surface was along the low strength, slickensided, contact zone located around the base of the Omahia Andesite. This shear zone was up to $80 \mathrm{~m}$ below the ground surface.

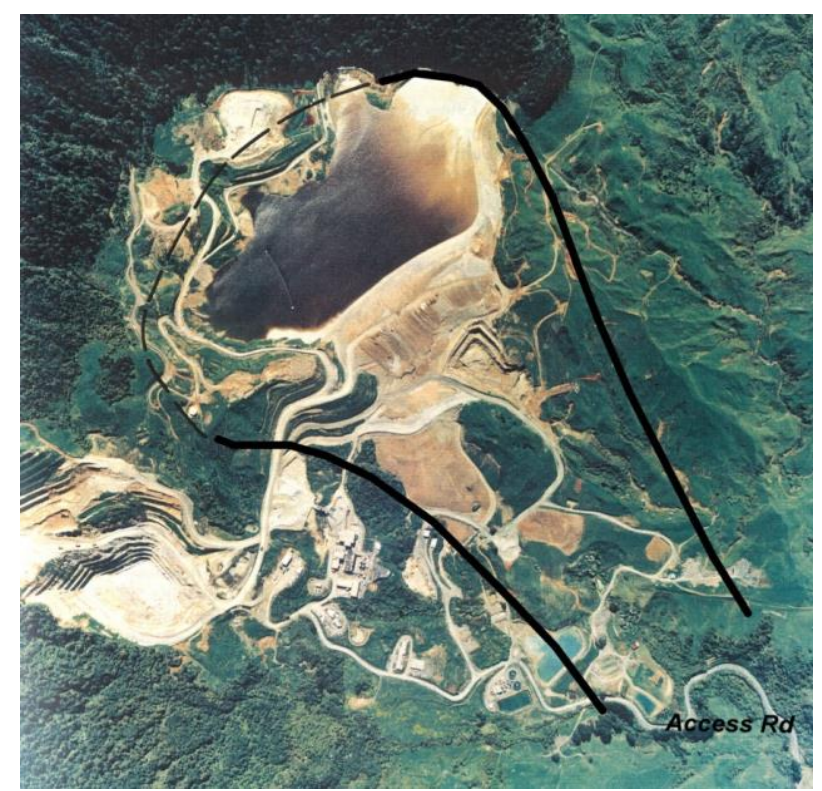

Figure 15 The approximate boundaries of the landslide at Golden Cross 


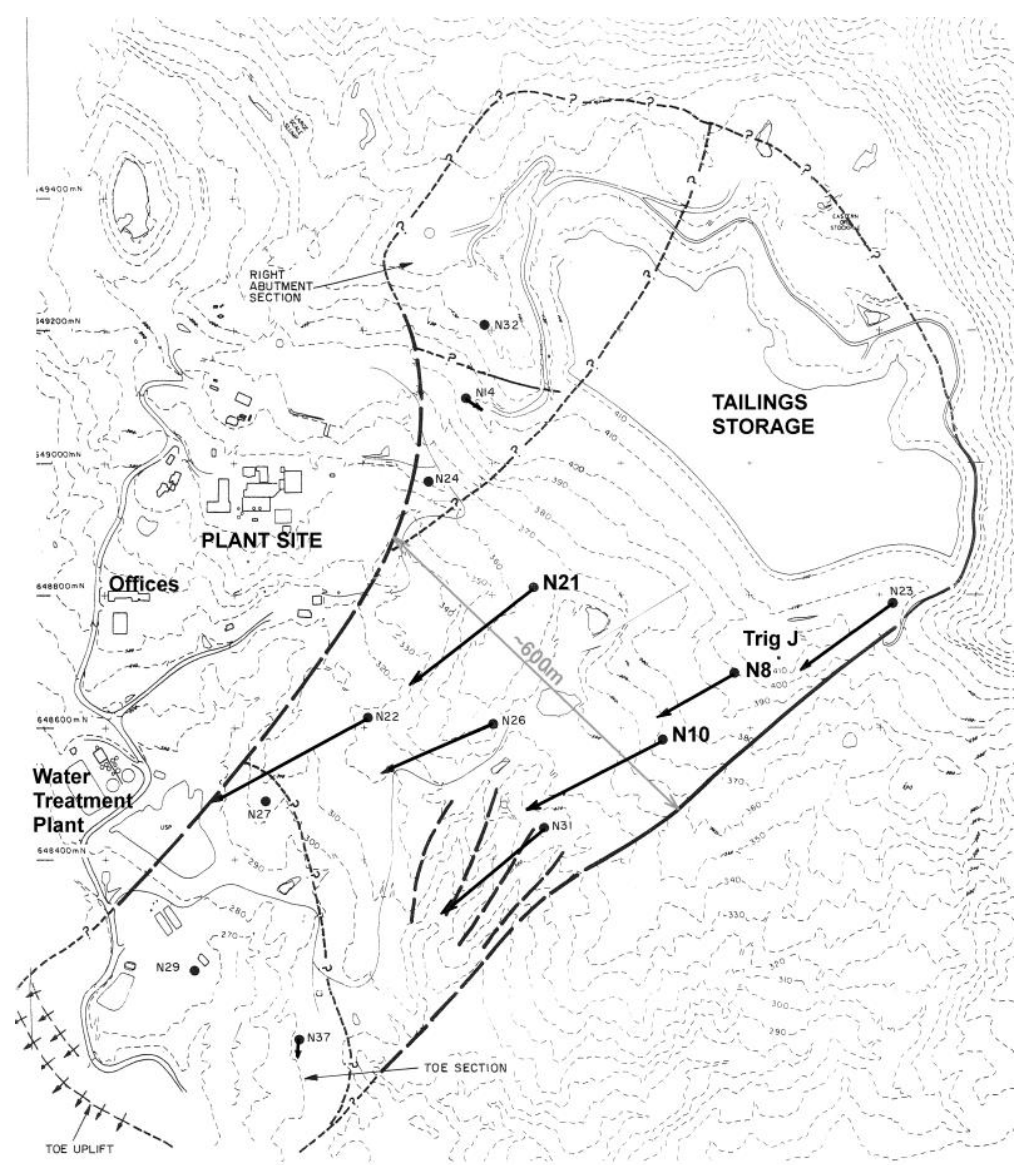

Figure 16 Vectors from inclinometers, showing interpreted landslide by PSM

This was not quite the end of the saga. Others refused to accept that the landslide extended across the access road, some $1.5 \mathrm{~km}$ from the dam. On the basis of this blinkered view it was decided to build a 'stabilising' fill uphill of the road. After much expenditure, the net effect was to accelerate landslide movements.

Within a year, the profitable mine was abandoned.

\section{The ugly: Heathrow Express tunnels}

\subsection{Location and magnitude of the Heathrow Express tunnel collapse}

"One of the worst civil engineering disasters in the United Kingdom in the last quarter of a century occurred during the night of 20-21, October 1994 when tunnels in the course of construction beneath Heathrow Airport's Central Terminal Area (CTA) collapsed. They continued to collapse over the following days. The public and those engaged in the construction work were exposed to grave risk of injury. Workers were evacuated from the tunnels minutes before the first collapse. Some had been carrying out repairs to critical parts of a tunnel lining while others had been advancing a parallel tunnel. By remarkable good fortune no one was injured. Major short-term disruption to the airport followed. The Heathrow Express Rail Link project of which the tunnels were a part, suffered a severe set-back."

The Collapse of NATM tunnels at Heathrow Airport', Health \& Safety Executive 1994.

In February 1999, the heaviest fines ever imposed, following prosecution by the British Health and Safety Executive (HSE), were levied against Balfour Beatty (GBP 1.3 million) and Geoconsult (GBP 0.6 million). Geoconsult's culpability related to aspects of design, monitoring and interpretation of monitoring of the NATM tunnelling - and to a failure to warn. 
Recovery from the collapse cost GBP 150 million, nearly three times the original contract (New Civil Engineer, 8 November 2012). The location is shown in Figures 17 to 19.

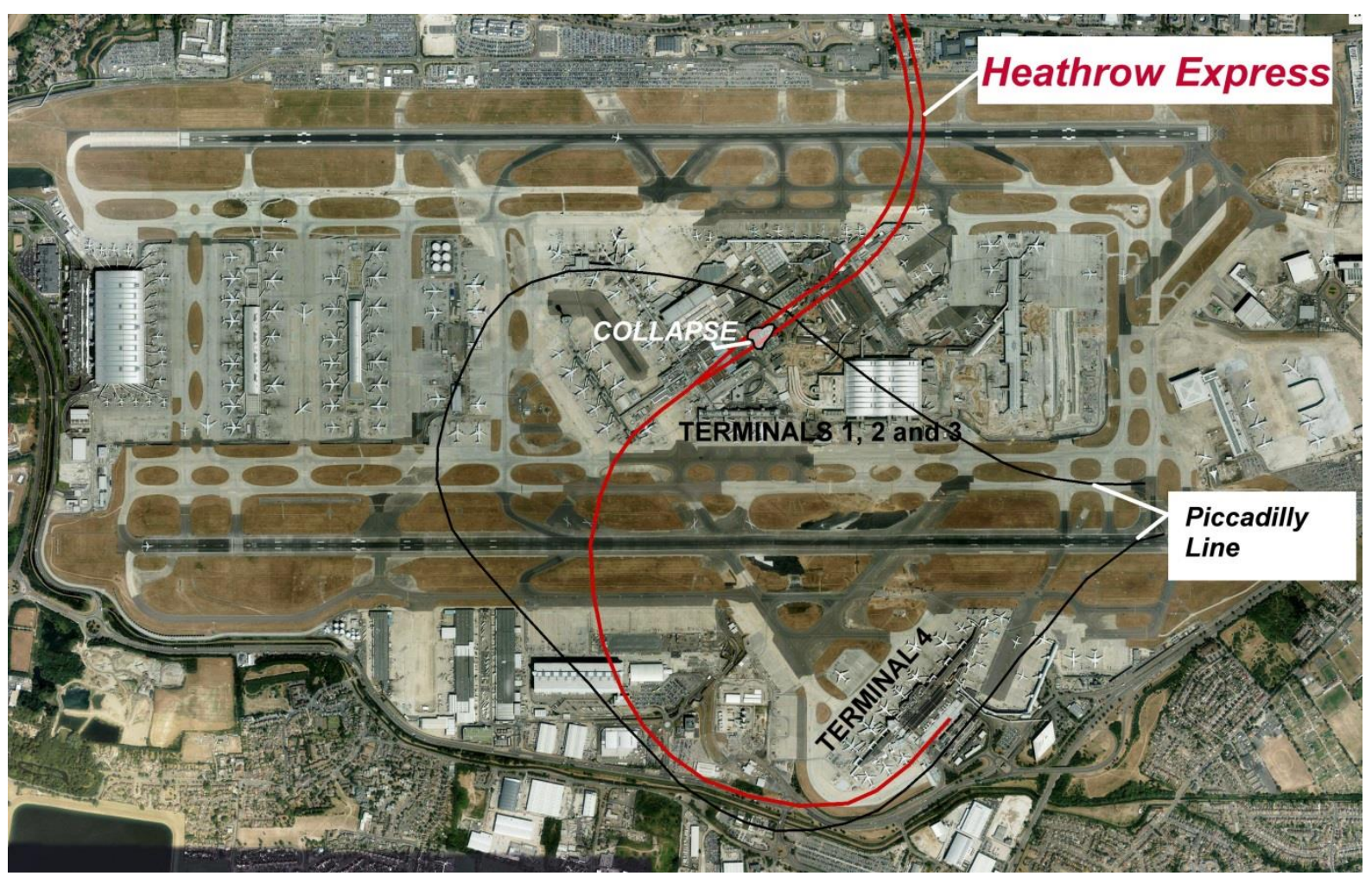

Figure 17 Location of the Heathrow Express collapse

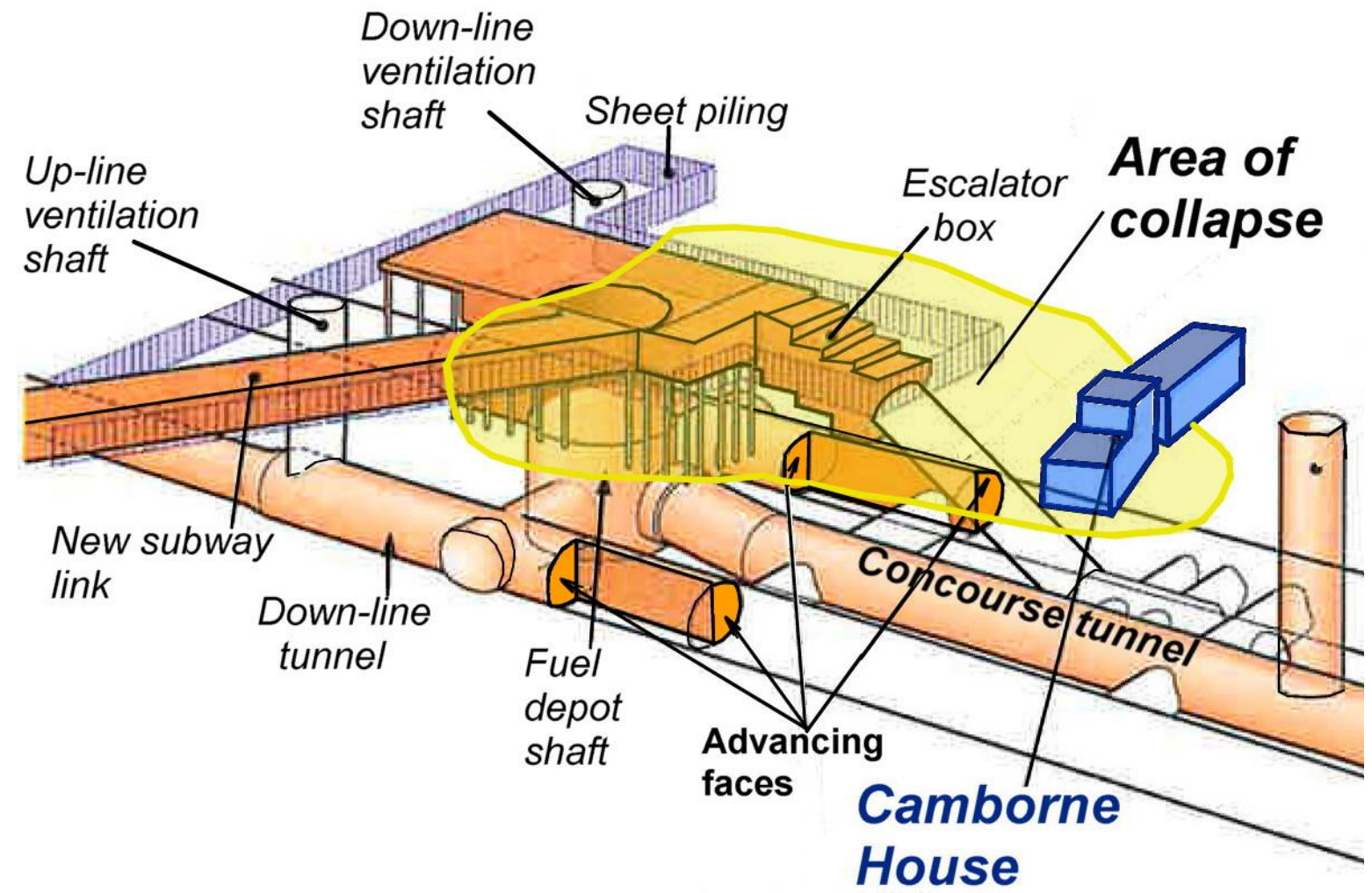

Figure 18 Perspective sketch of tunnels at time of failure 


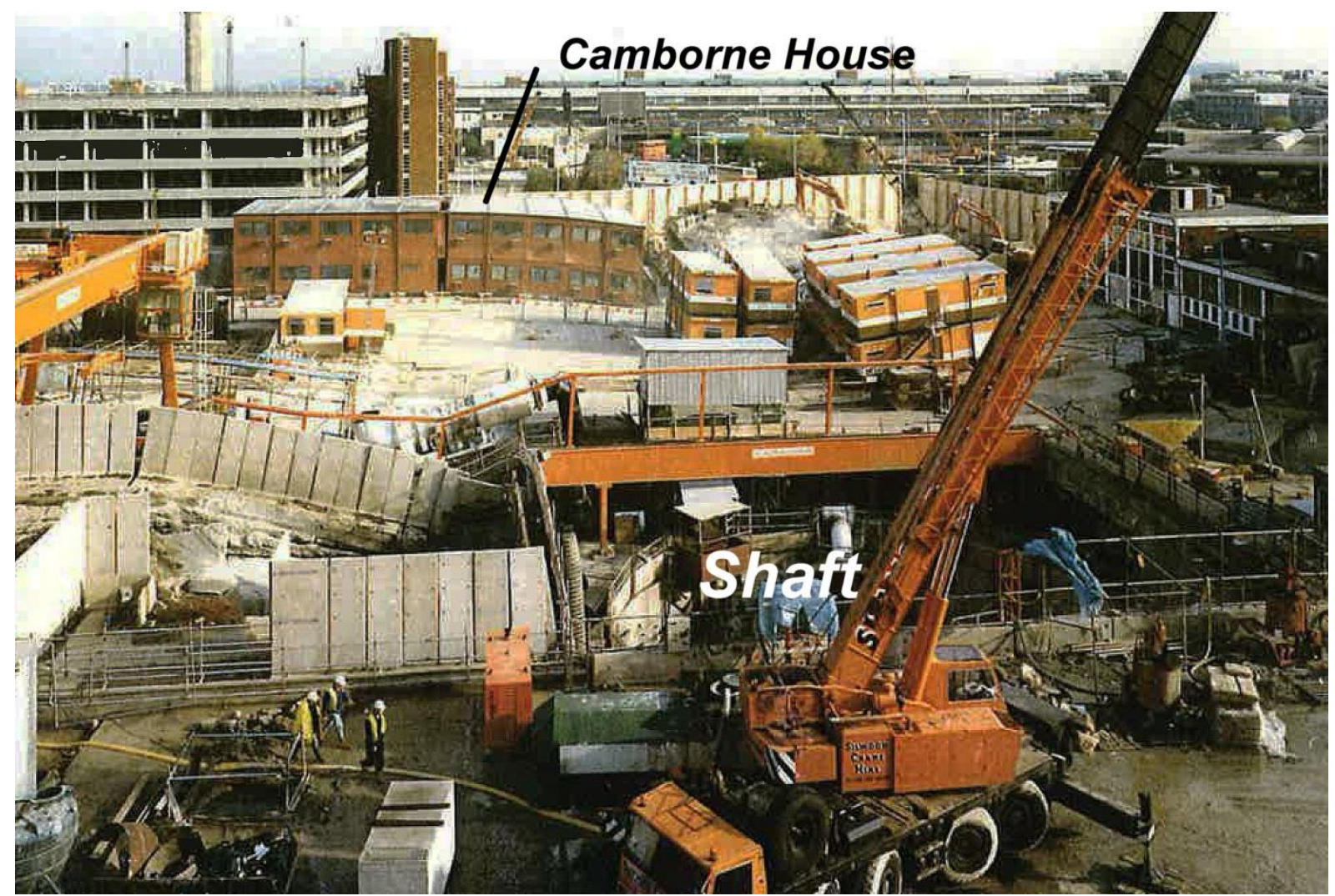

Figure 19 Surface damage view from top left of Figure 19

Contours of settlement over the area of about a rugby field are shown in Figure 20.

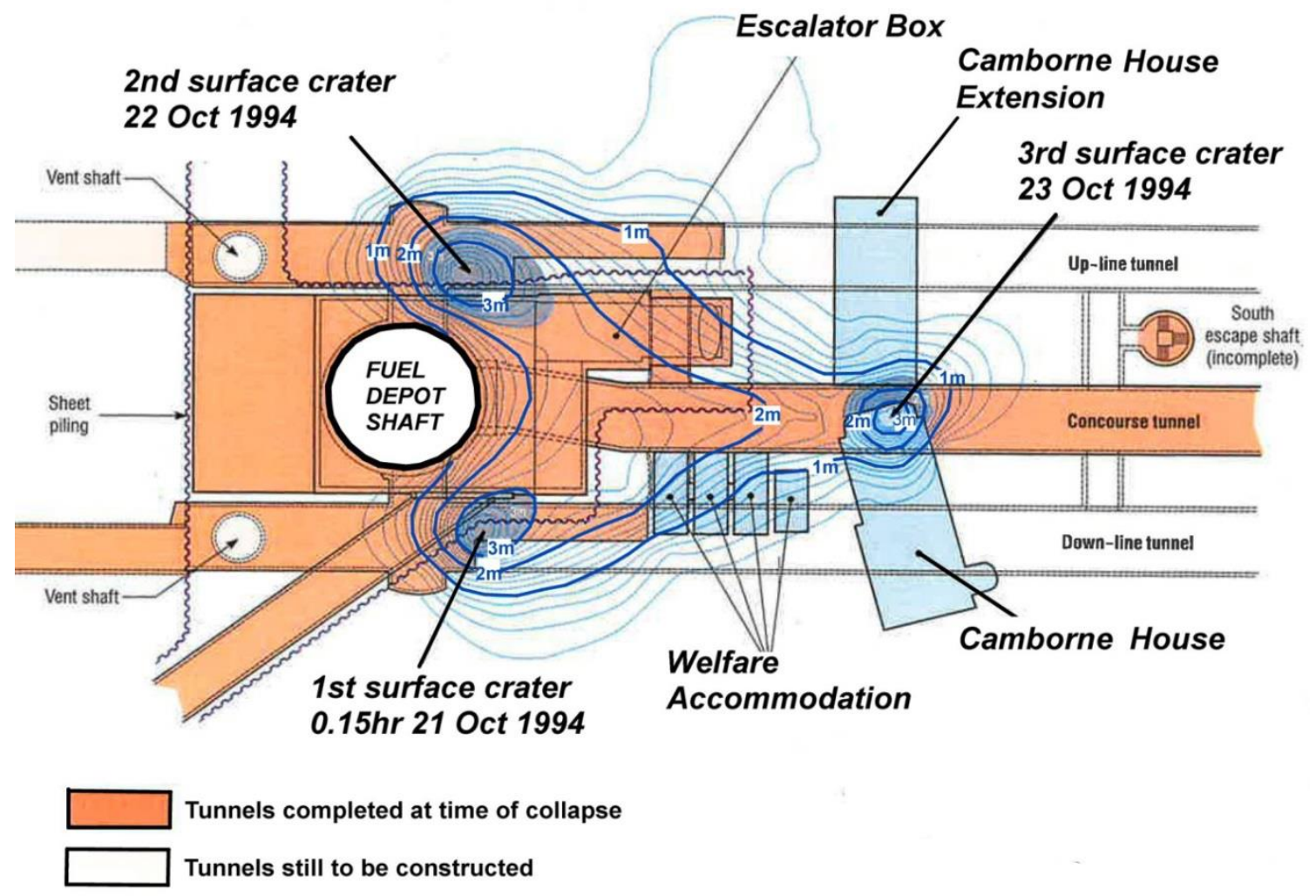

Figure 20 Surface settlement, in excess of $3 \mathrm{~m}$ at three 'bulls-eyes' (Health \& Safety Executive 1994) 


\subsection{Forensic findings}

The forensic report by the HSE found:

"Although the linings were especially vulnerable from the effects of poor workmanship, they could have been safely constructed. However, the margin for error was small and rigorous inspection and monitoring during construction was necessary." (this author's underline)

and

"More generally, predefined trigger levels against which to monitor magnitudes and rates of change were not set by the designer as a part of the design."

and

"Management systems and resources capable of collecting, inputting, processing and interpreting the large amounts of instrumentation data were required. Geoconsult's site engineer was hard pressed. Additionally, he only worked during the day shifts from Monday to Friday; but NATM tunnelling construction, and the need for expert support, went around the clock, seven days a week.

His workload increased when the project fell behind programme and additional tunnels were started to try to make up time. It should have been apparent that Geoconsult's site engineer was overloaded."

Sir Alan Muir Wood noted that recorded monitoring data and other contemporaneous evidence indicated imminent collapse up to 14 days before the event of 21 October 1994 (Figure 21).

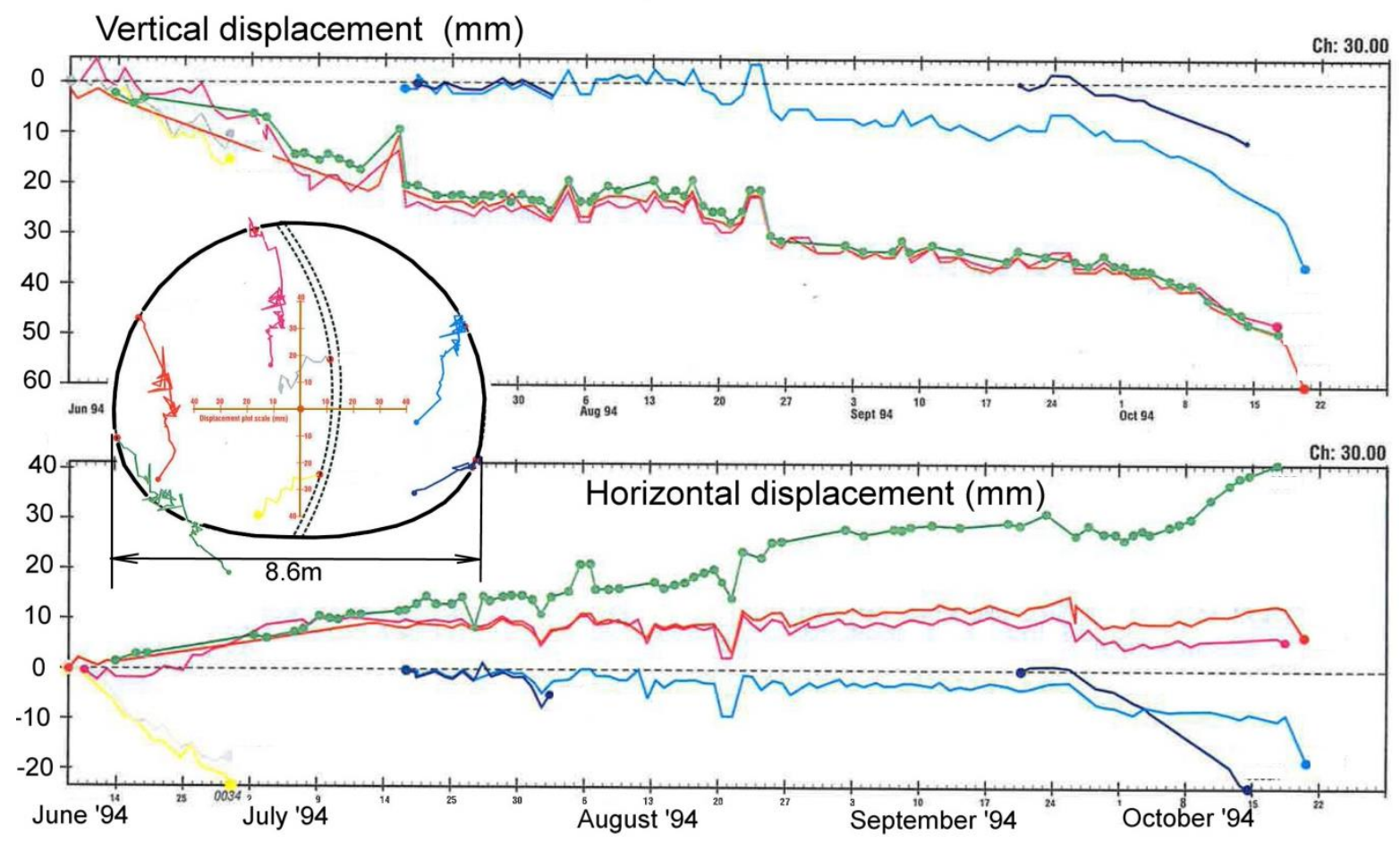

\section{Figure 21 Summary of monitoring data (modified from HSE 1994)}

Another European forensic engineer noted that, despite limited instrumentation and inadequate software for processing the data, there was sufficient recorded data to indicate the high probability of failure, and the failure mechanism (Wallis 1999).

Most importantly, the HSE report stated:

"The collapses could have been prevented but a cultural mind-set focused attention on the apparent economies and the need for production rather than the particular risks." 
This cultural mindset is, in effect, the point made by Kahneman in his book, 'Thinking, fast and slow'. He shows that our so-called rational thinking (his System 2) is substantially influenced by our autonomic thinking, (his System 1), viz:

"System 2 is more of an apologist for the emotions of System 1 than a critic of those emotions - an endorser rather than an enforcer. Its search for information and arguments is mostly constrained to information that is consistent with existing beliefs..."

The ramifications of this point are picked up in the conclusions to this paper.

\section{$5 \quad$ The very ugly: Vaiont Dam, Italy}

\subsection{The tragedy}

On 9 October 1963, about 260 million $\mathrm{m}^{3}$ of rock slid from the side of Monte Toc into the reservoir of the Vaiont Dam in less than 45 seconds, with an estimated velocity of 20 to $30 \mathrm{~m} / \mathrm{s}$ (Figures 22, 23 and 24). The $276 \mathrm{~m}$ high double curvature concrete arch dam, then the highest in the world, did not fail (Figure 25); almost 2,000 people died (Genevois \& Ghirotti 2005).

I visited the site in 1968 and it remains the most extraordinary thing I have seen in my life.

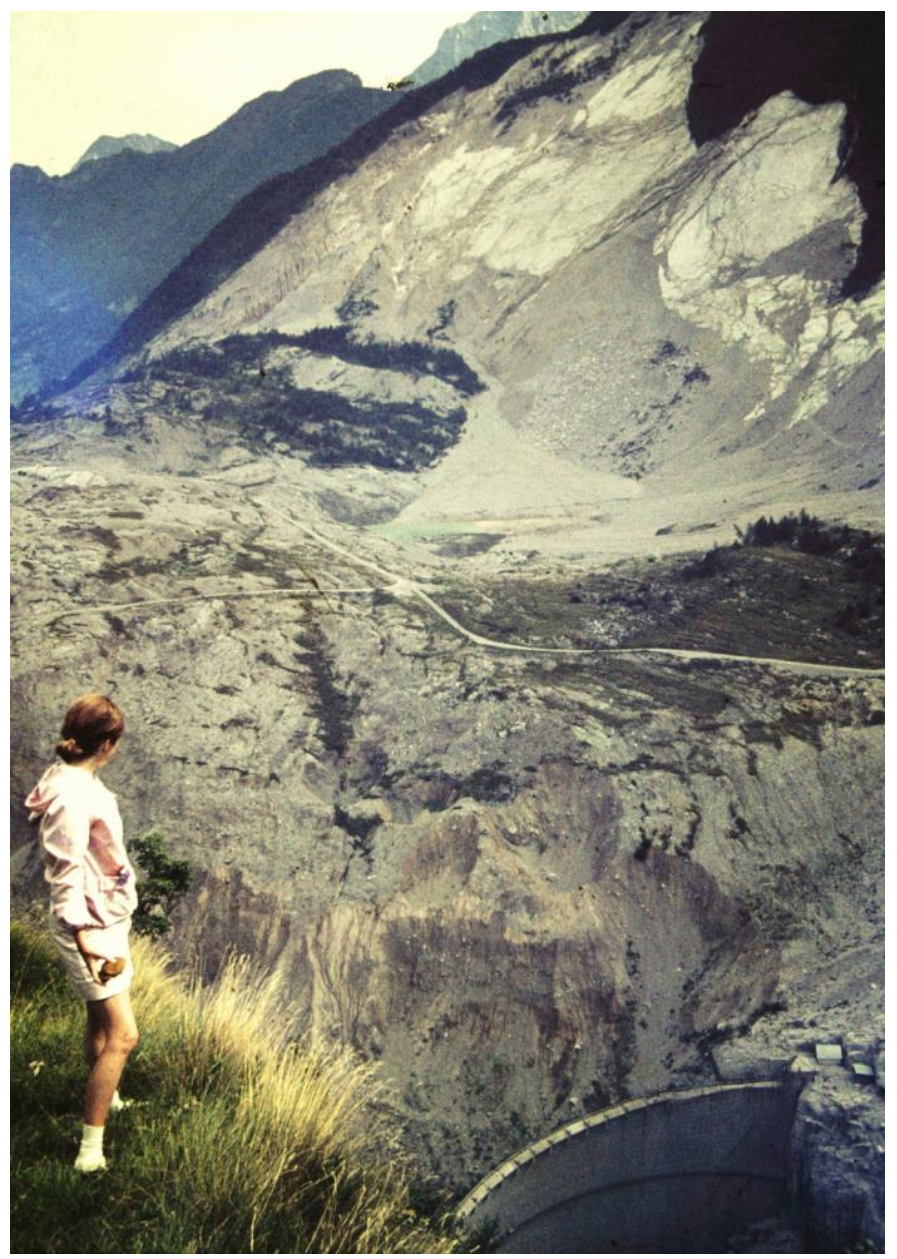

Figure 22 Helen Pells on the mountainside above the crest of the $\mathbf{2 7 6} \mathbf{m}$ high arch dam, 1968 


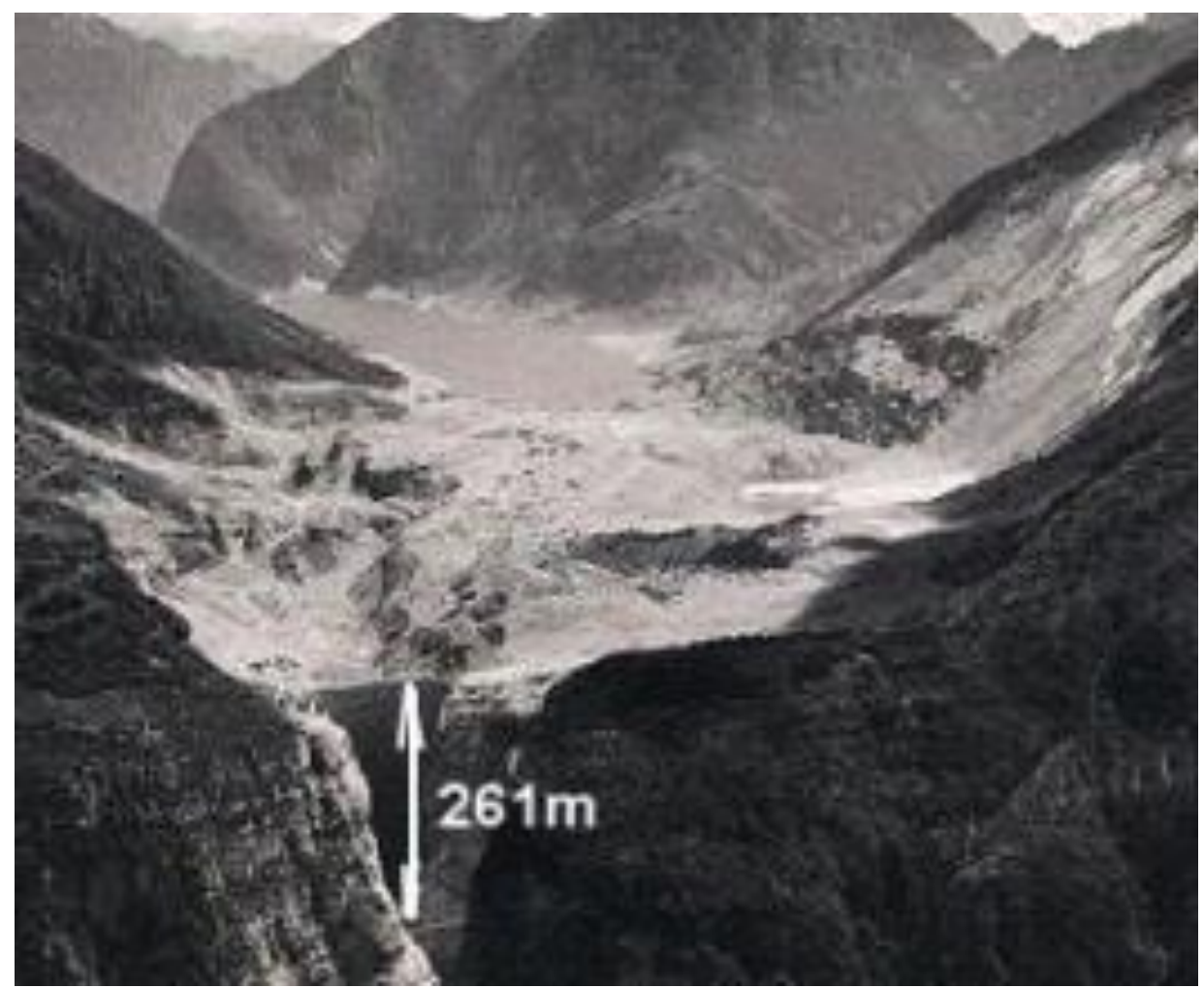

Figure 23 Oblique aerial photo shortly after the failure

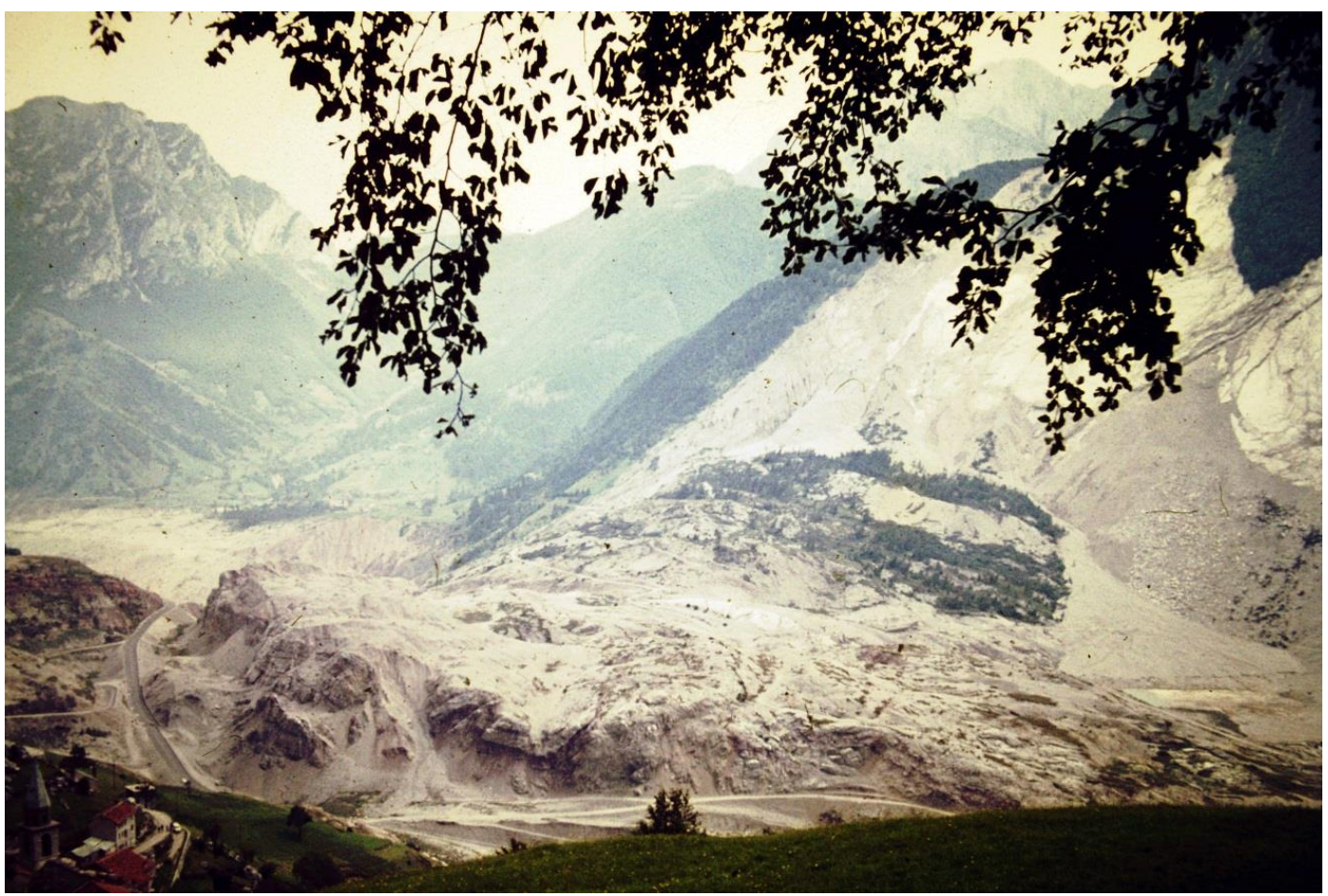

Figure 24 The extent of the slide from above the village of Casso (lower left corner) that was partly swept away (photo Pells, 1968) 


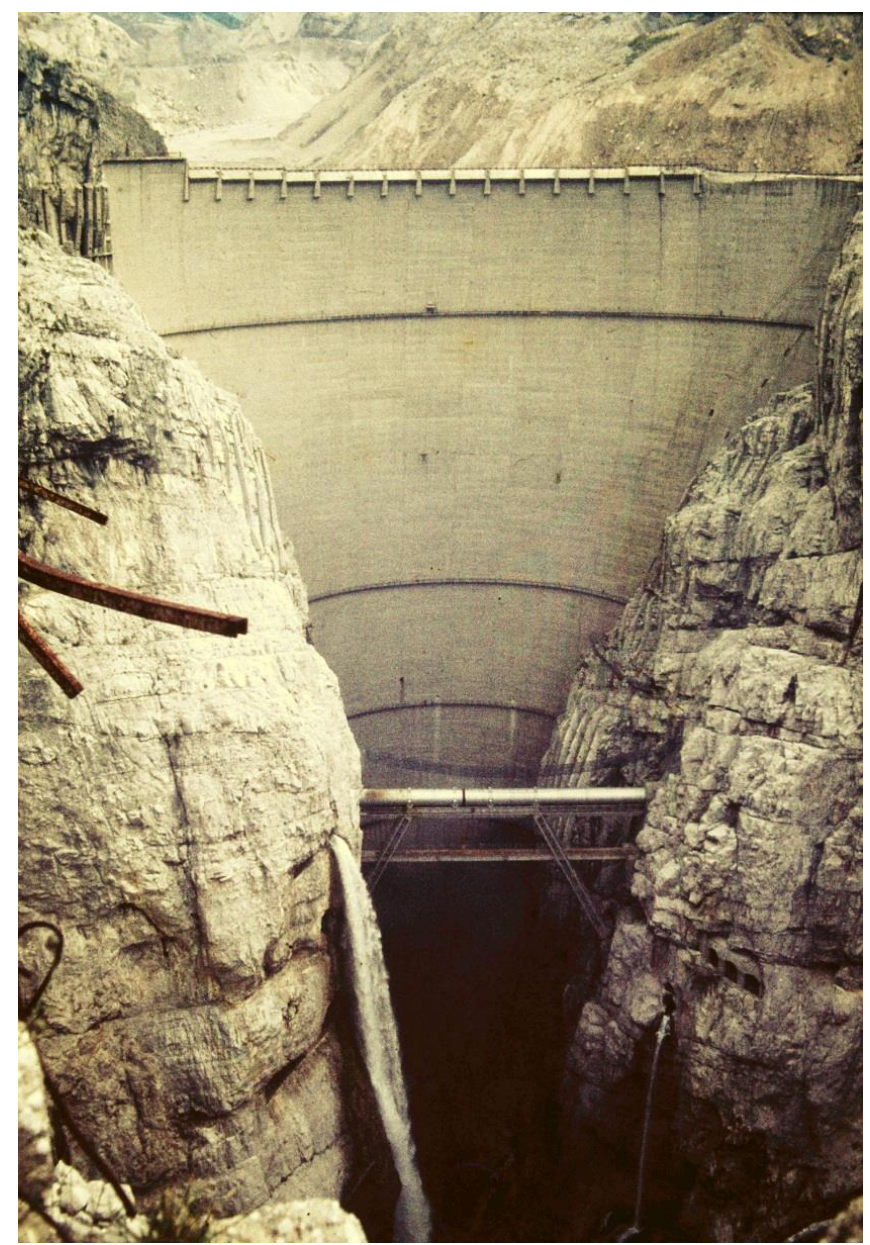

Figure 25 The arch after the wave had passed over the crest - note the abraded concrete reinforcing $0.5 \mathrm{~km}$ downstream and $300 \mathrm{~m}$ above the valley floor (photo Pells, 1968)

The entire mass slid approximately $500 \mathrm{~m}$ northwards, at up to $30 \mathrm{~m} / \mathrm{s}$. The slide completely blocked the gorge to a depth of up to $400 \mathrm{~m}$, and it travelled up to $140 \mathrm{~m}$ up the opposite bank. Movement of the landslide mass ceased after a maximum of $45 \mathrm{~s}$. The reservoir contained 115 million $\mathrm{m}^{3}$ of water. A wave of water was pushed up the opposite bank and destroyed the lower part of the village of Casso, $260 \mathrm{~m}$ above lake level. The displaced water then overtopped at more than $100 \mathrm{~m}$ above the crest.

An estimated 30 million $\mathrm{m}^{3}$ fell into the narrow gorge of the Vaiont River, roared out into the Piave valley and destroyed the villages of Longarone (Figures 26 and 27), Pirago, Villanova and Rivalta. 


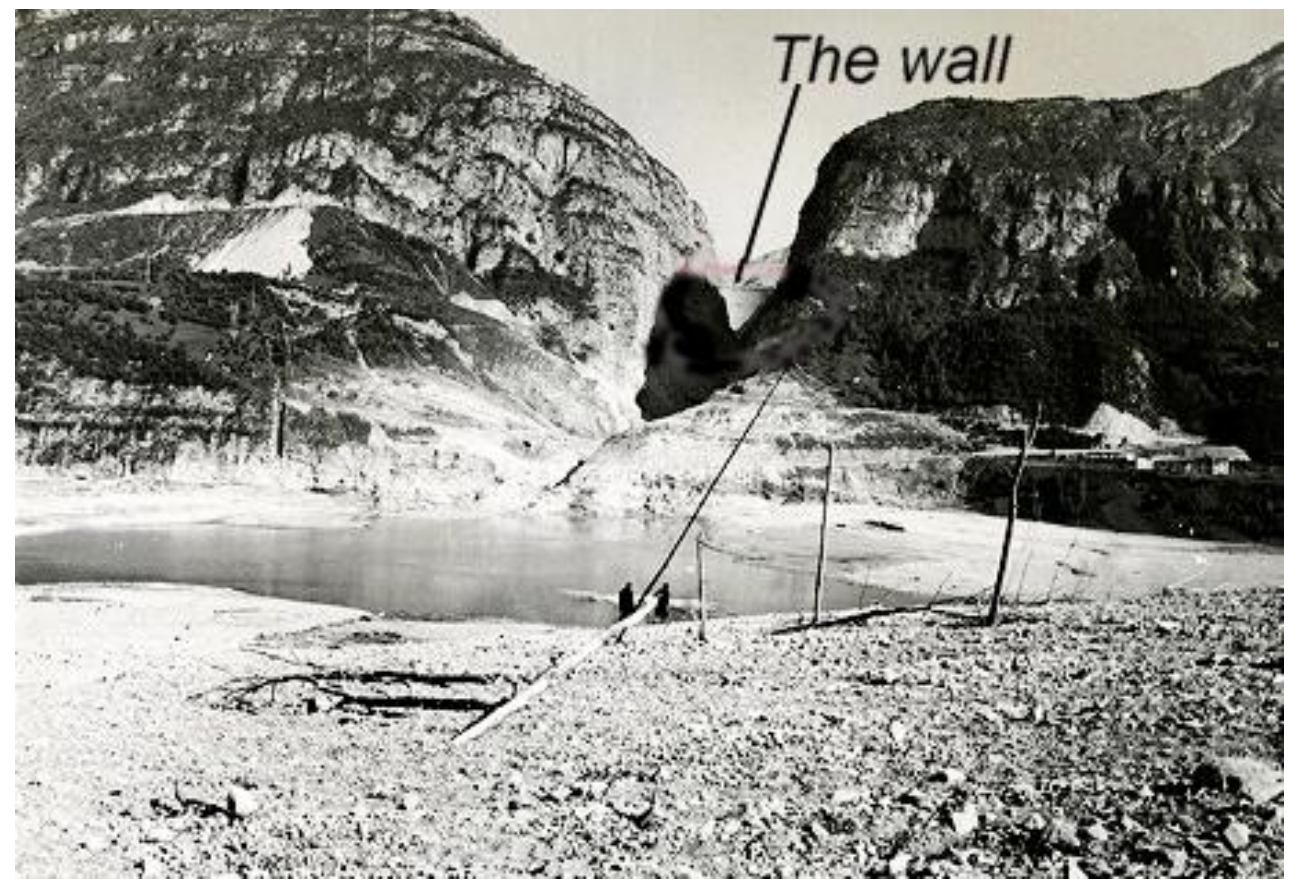

Figure 26 Looking up towards the dam from what was Longarone, shortly after the tragedy

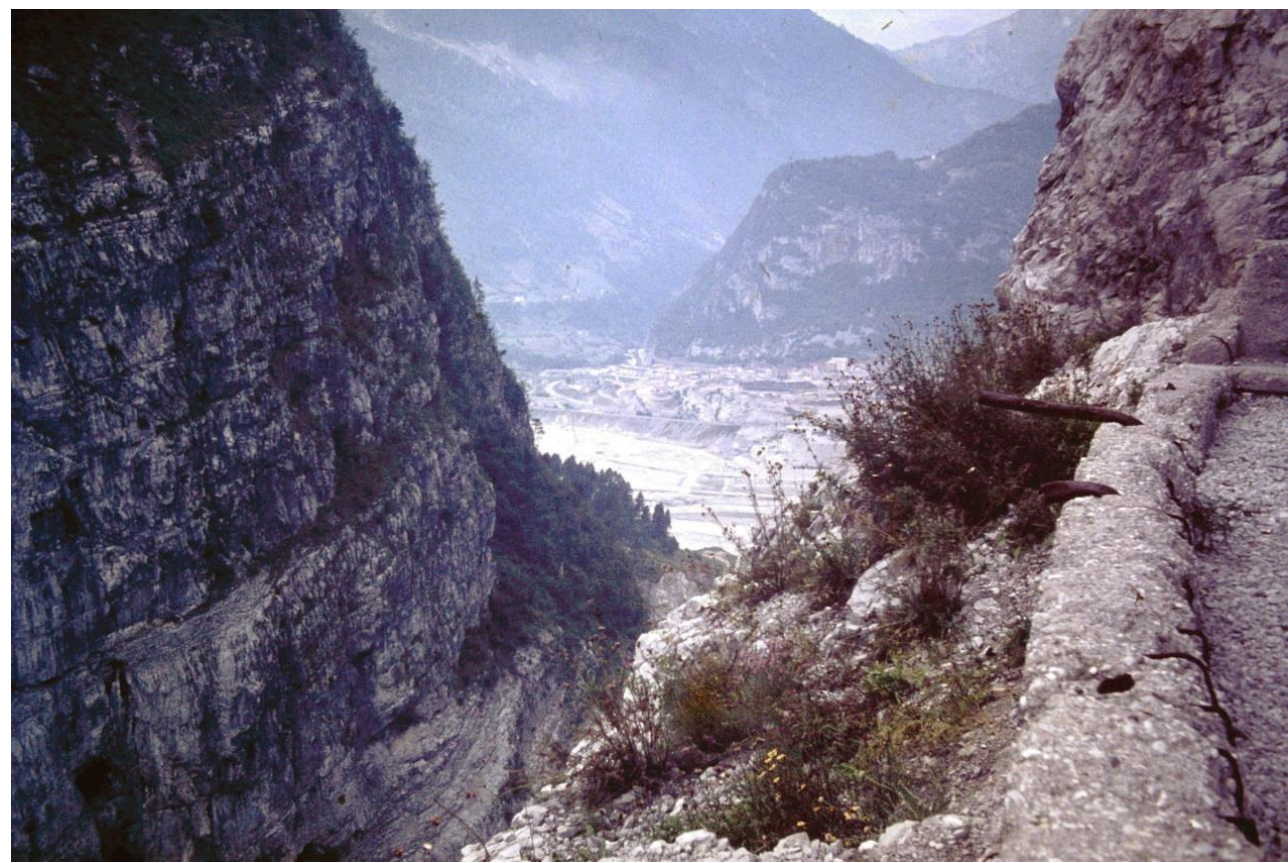

Figure 27 View downstream from same point as Figure 26. The remains of the village of Longerone can be seen at the mouth of the gorge. Note again, as per Figure 26, the abraded reinforced concrete wall

\subsection{The geology and the monitoring}

Movement of the mountainside had become apparent in 1960 shortly after the wall was completed. Extensive monitoring was implemented some of which is summarised in Figures 28 and 29. 


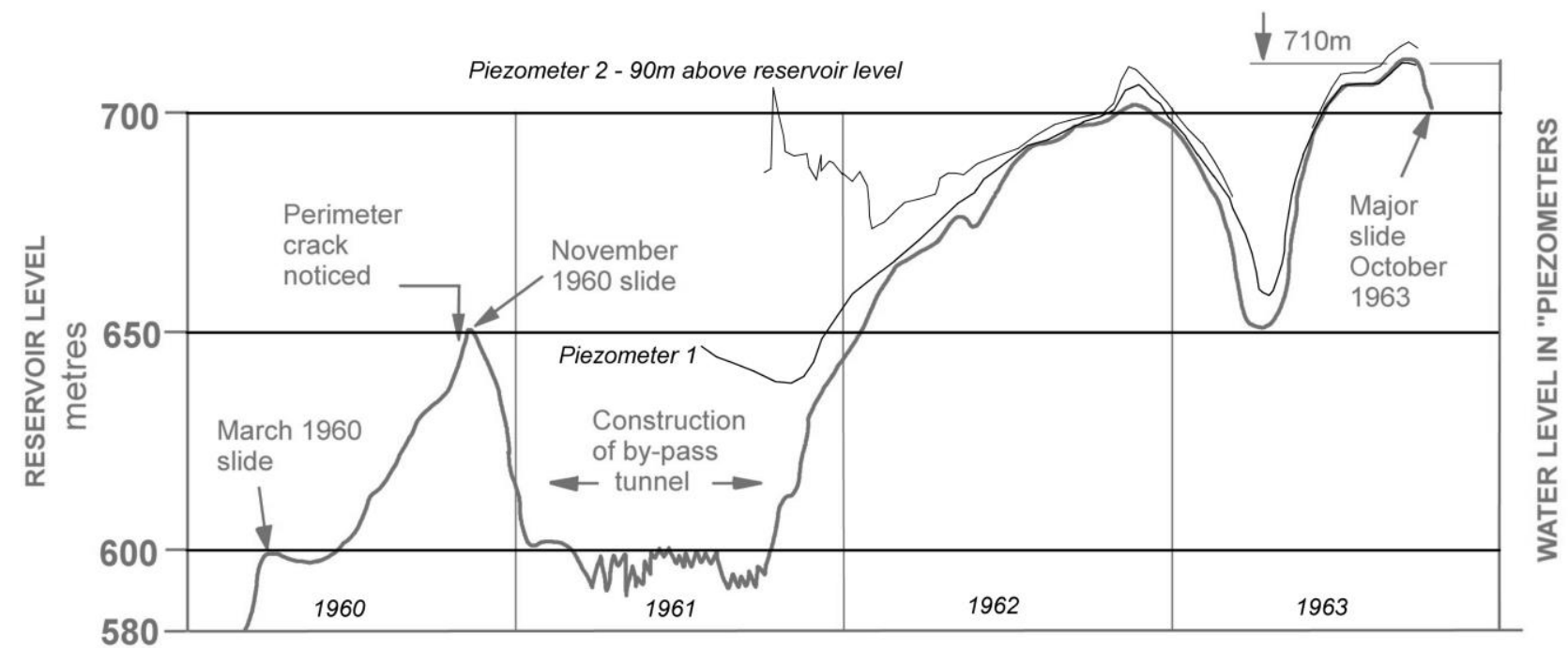

\section{Figure 28 Plots of reservoir and piezometer levels}

As can be seen from Figures 28 and 29, the lake level started to be raised again during April 1963. Movements started again after the reservoir level reached $700 \mathrm{~m}$. Velocity remained low until, in early September, at a lake elevation of $710 \mathrm{~m}$, the rate of slope movement increased from 5 to $10 \mathrm{~mm} /$ day. This continued to increase throughout September, reaching 20 to $40 \mathrm{~mm} /$ day at the beginning of October (Figures 29 and 30).

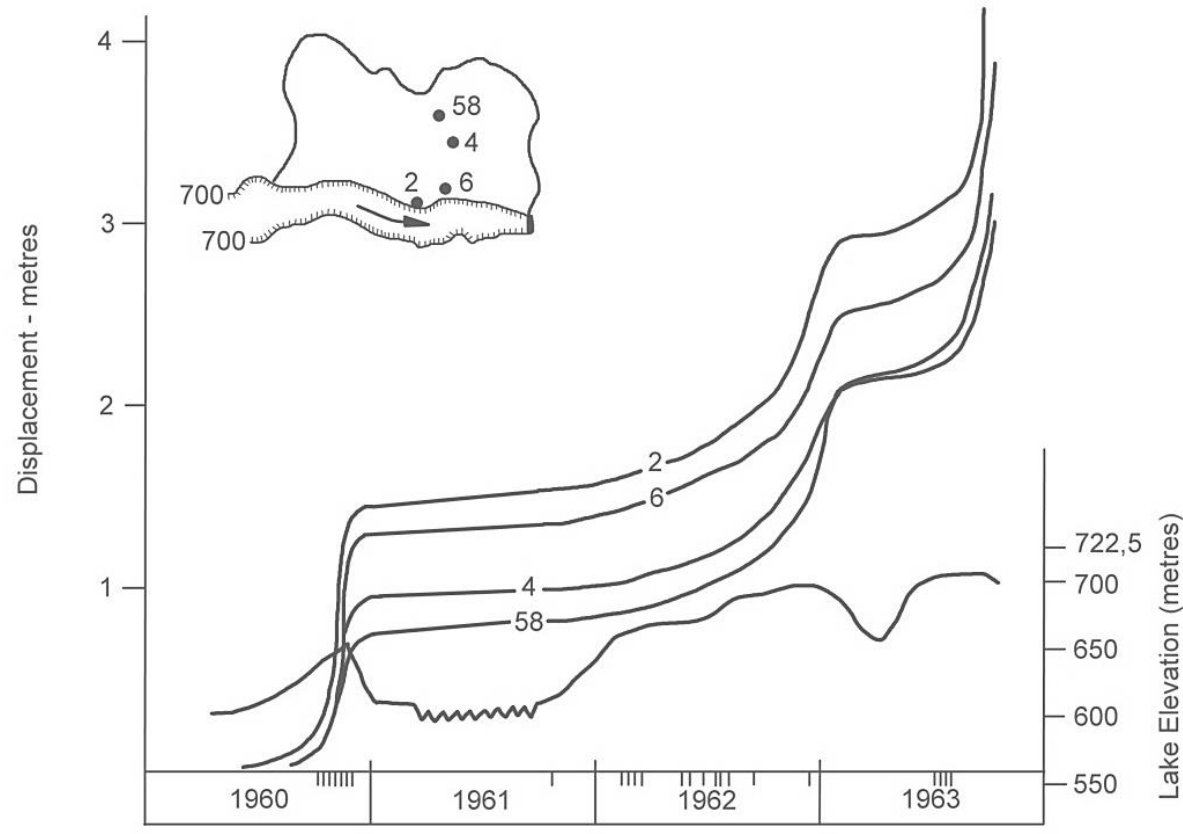

\section{Figure 29 Plots of displacements versus time}

The reservoir was lowered to about $700 \mathrm{~m}$ but the velocity increased up to $200 \mathrm{~mm} /$ day. At $2239 \mathrm{~h}$ on 9 October 1963, the southern rock slope of Mount Toc failed (Figure 31). 


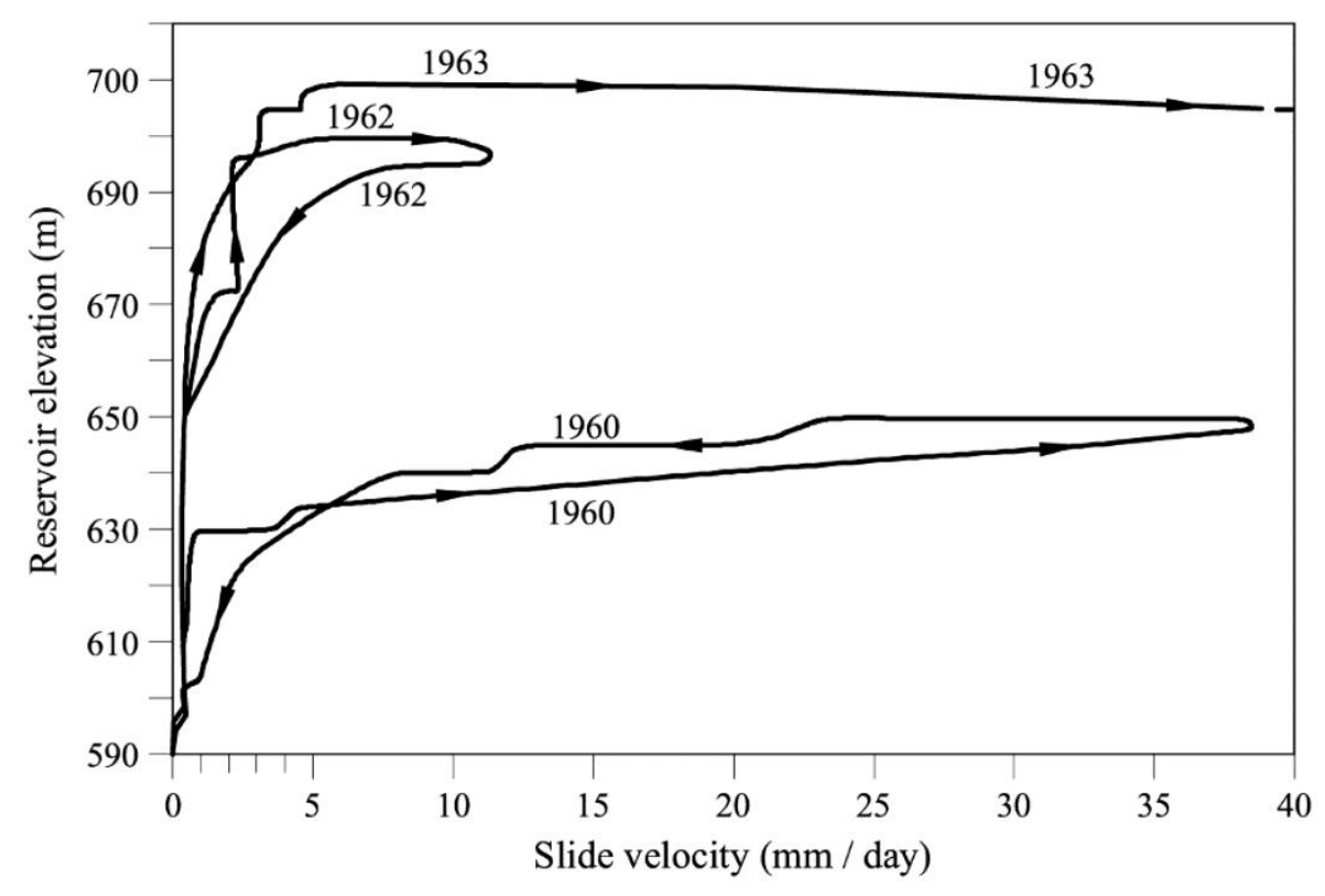

Figure 30 Slide mass velocities pre-failure

The idea had been developed to 'manage' the landslide by manipulating reservoir water levels. The slide was supposed to move gently into the reservoir, separating the main storage area from the wall and turbine intakes. So a bypass tunnel was constructed on the opposite side to connect the remaining reservoir to the turbines.

The magnitude of the landslide that actually occurred had been discounted by almost all, except the 32-year-old geologist Eduardo Semenza (Genevois \& Ghirotti 2005). As a twist of fate, Eduardo was the son of the designer of the dam, Carlo Semenza, who initially was sceptical of his son's findings (Guzzetti \& Lollino 2011). Carlo died two years before the disaster.

From fieldwork, Eduardo identified geomorphological features that he correctly interpreted as evidence of a very large, ancient landslide deposit, extending some $1.5 \mathrm{~km}$ along the left flank of the reservoir area. He postulated that this landslide had filled the valley after the retreat of the Würm glacier. Subsequently a new Vaiont river cut through the deposit leaving most of the original slip mass on the left flank, and a portion on the right side. This portion was subsequently called Colle Insolata. In the failure, Colle Insolata was pushed up the right flank of the valley (Figure 31). 


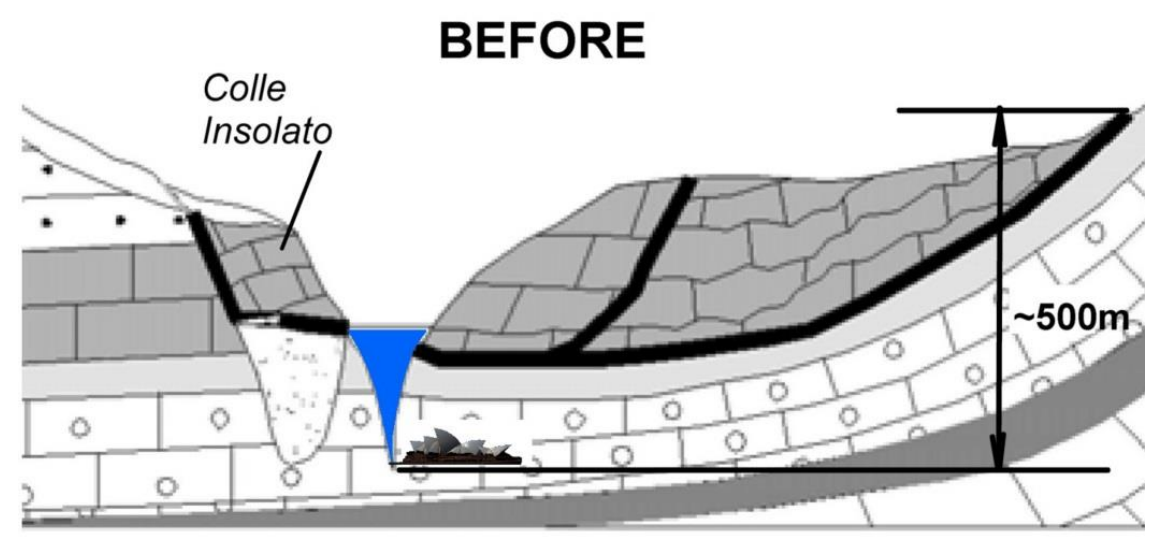

\section{AFTER}

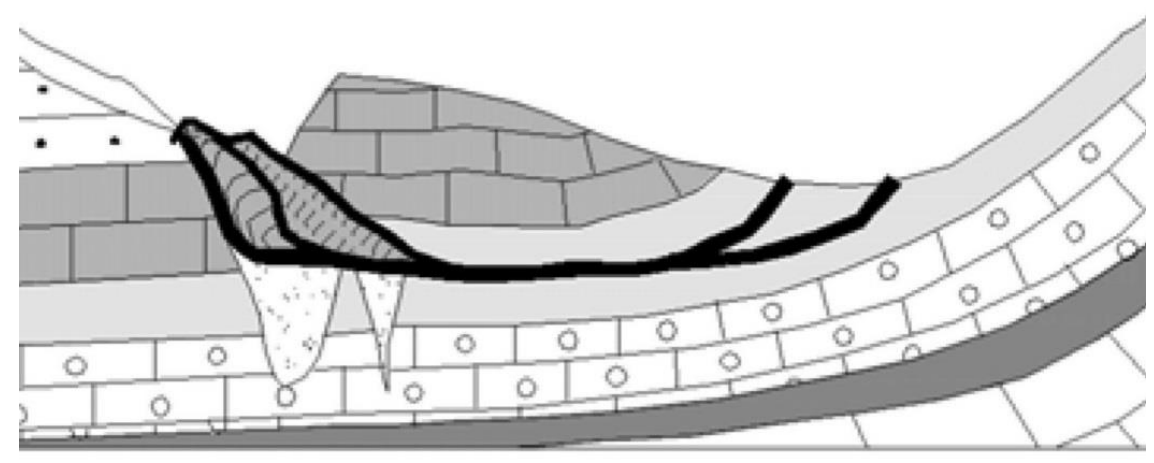

\section{Figure 31 Cross-section before and after. Note the Sydney Opera House to scale in the upper section}

Whilst Leopold Muller accepted the geomorphological evidence, others did not, and debate raged as to whether there would be small slides, large slides, slow slides or fast slides. There was 'continuous rejection of the worst case scenario - a gigantic single landslide - by the authorities, by the electric power company and the government' (Genevois \& Ghirotti 2005).

Nobody predicted what happened and, to this day, there is no consensus as to why it moved so suddenly and so quickly (Figures 32 and 33).

Initially there was a large amount of speculation about the location of the sliding surface, but studies have confirmed that it was located in thin $(50$ to $150 \mathrm{~mm}$ ) clay layers within the limestone. Whilst most consider it was reactivation of an ancient landslide, Skempton and others were of the view it was a first-time failure.

For a wonderful detailed discussion of the landslide, see Chapter 2 of 'Geomechanics of Failures, Advanced Topics' (Alonso 2010). 


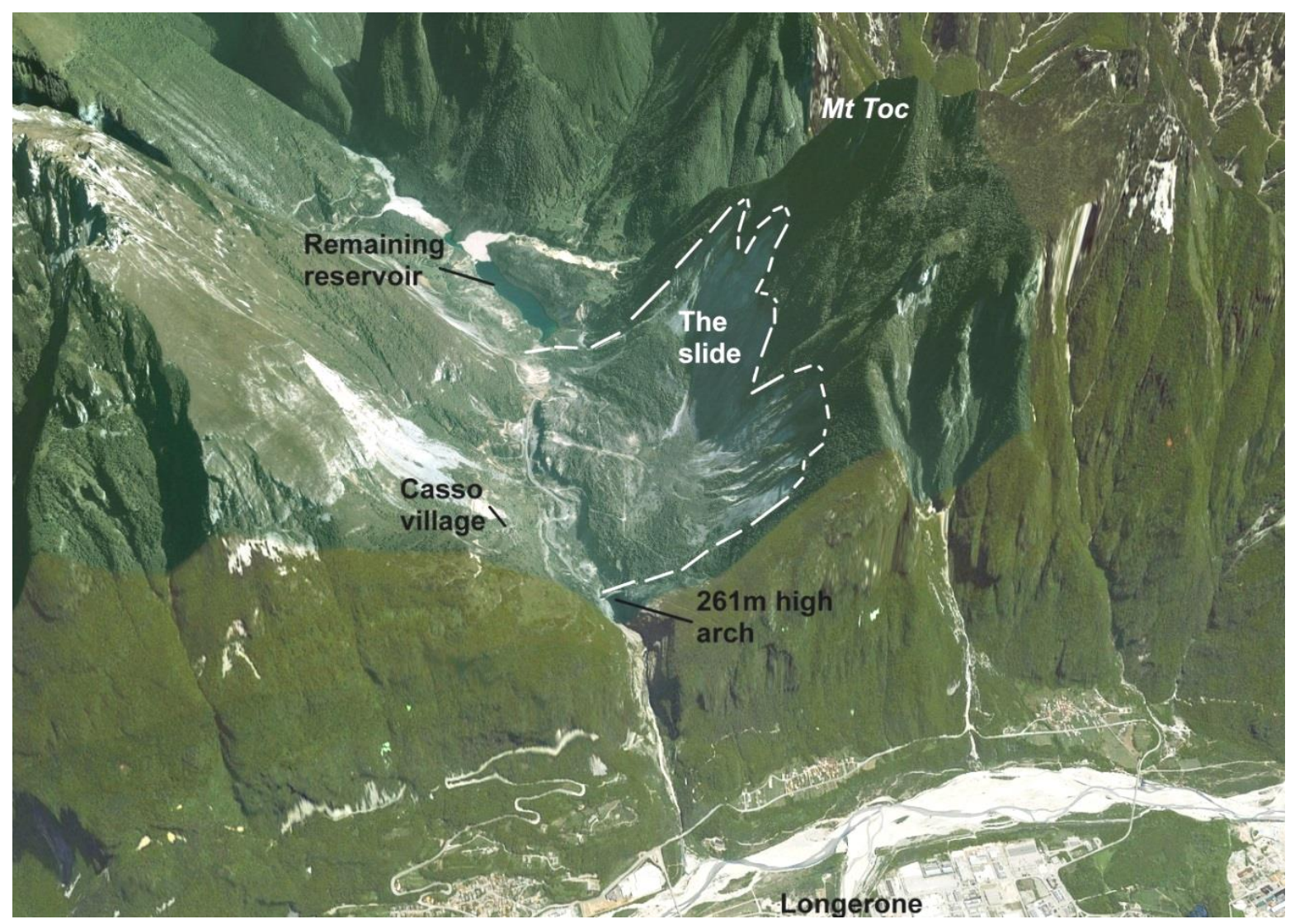

Figure 32 3D view of the landslide area - Google Earth 2012

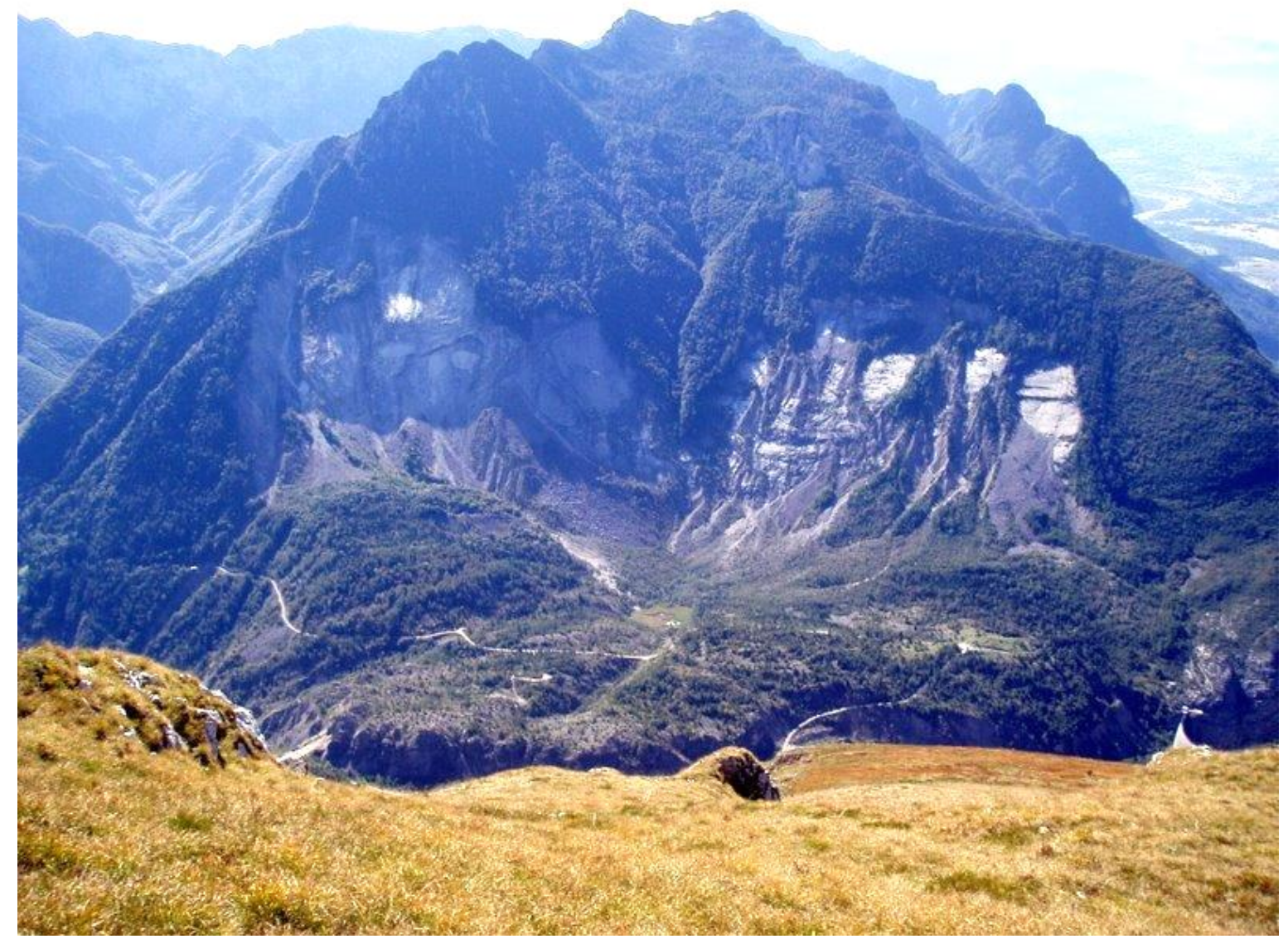

Figure 33 The landslide area 2013 


\section{Discussion}

Some easy conclusions can be drawn from the stories presented above, and I reach these with substantial help from Daniel Kahneman (2011).

1. Monitoring, whether by simple survey or complex transducer measurements, should be implemented only with a valid model against which to evaluate the results. That model may be geological or analytical. There should be predictions against which the monitoring data are evaluated. Of course, there is a class of problem, such a plate load tests, where the measurements are to deduce one or more parameters, but inherent in such cases are analytical models.

2. Be aware that, like all humans, you carry cognitive bias that will influence your logical thinking to the extent of being illogical. If you designed a thing, you cannot readily accept its failure - you will be blind to the signs. I call this bias, that we all carry emotional baggage. Kahneman shows there are variations, such as outcome bias and affect heuristic. You may find these terms easier if you want to delude yourself that your thinking is not affected by emotion. The psychologist Haidt (2000) says, "the emotional tail wags the rational dog."

3. Remember that the data you have is a small part of the whole story. "You cannot help dealing with the limited information you have as if it were all there is to know. You build the best possible story from the information available to you, and if it is a good story, you believe it. Paradoxically, it is easier to construct a coherent story when you know little, when there are fewer pieces to fit in the puzzle. Our comforting conviction that the world makes sense rests on a secure foundation; our unlimited ability to ignore our ignorance" (Kahneman 2011).

4. Listen to those who do not agree with you; again, as Kahneman says, "the illusions of validity and skill are supported by a powerful professional culture. We know that people can maintain an unshakable faith in any proposition, however absurd, when they are sustained by a community of like-minded believers" (Kahneman 2011).

5. Do not just rely on numerical monitoring data, ensure you have a good geological model, and listen to wise and experienced geologists. They often see things that engineers miss completely.

Then there is a difficult point, which relates to extreme events, such as the Vaiont landslide.

I suggest that the violence of the Vaiont landslide was a 'Black Swan', an extreme event that could not be predicted (Taleb 2007). This kind of thing must be borne in mind whenever our monitoring data indicate that the structure, or facility, may be approaching failure. In such scenarios, 'errors of prediction are inevitable, because the world is unpredictable'.

The best solution is stay, and play, far away from the tipping point of collapse - but if you find yourself there, you are in a near-impossible place. Cry failure from the rooftop and you run the risk of being a scaremonger; whisper all is well, and you could be an idiot condemning people to death. Personally, I choose to be a scaremonger.

\section{References}

Alonso, EE, Pingol, NM \& Puzrin, AM 2010, Geomechanics of failures: advanced topics, Springer Science, Dordrecht.

Genevois, R \& Ghirotti, M 2005, 'The 1963 Vaiont landslide', Giornale di Geologia Applicata 1, pp. 41-45.

Guzzetti, F \& Lollino, G 2011, 'Book review of "the story of Vaiont told by the geologist who discovered the landslide"', Natural Hazards and Earth System Sciences, vol. 11, pp. 485-486.

Haidt, J 2000, The Emotional Dog and its Rational Tail: A Social Intuitionist Approach to Moral Judgement, Psychological Review 108, pp. 814-834.

Health \& Safety Executive 1994, The Collapse of NATM tunnels at Heathrow Airport, London.

Kahneman, D 2011, Thinking, fast and slow, Allen Lane, an imprint of Penguin Books.

Pells, PJN \& Best, RJ 1991, 'Aspects of primary support design for tunnels in the Sydney basin', Trans Inst. Engineers, Australia.

Pells, PJN 2011, The Sydney Opera House carpark and the double helix, WriteLight, Blackheath, NSW.

Taleb, NN 2007, The black swan: the impact of the highly improbable, Random House, New York.

Wallis, S 1999, Heathrow failures highlight NATM (abuse?) misunderstandings', Tunnel 3/99 66-72. 